\title{
VERTICAL AND INCLINED EDGE-INDENTATION OF FRESHWATER ICE SHEETS
}

CENTRE FOR NEWFOUNDLAND STUDIES

\section{TOTAL OF 10 PAGES ONLY MAY BE XEROXED}

(Without Author's Permission)

DAVID W. FINN, B.Eng. 




\title{
VERTICAL AND INCLINED
}

EDGE-INDENTATION OF

\section{FRESHWATER ICE SHEETS}

\author{
BY
}

(cDavid W. Finn, B. Eng.

\begin{abstract}
A thesis submitted to the School of Graduate Studies in partial fulfillment of the requirements for the degree of Master of Engineering
\end{abstract}

Faculty of Engineering and Applied Science Memorial University of Newfoundland May 1991 
Canadian Theses Service Service des thèses canadiennes

Otuawa, Canada

KIA ONA

The author has granted an irrevocable non. exclusive licence allowing the National Library of Canada to reproduce, finn, distribute or sell copies of his/her thesis by any means and in any form or format, making this thesis available to interested persons.

The author retains ownership of the copyright in his/her thesis. Neither the thesis nor substantial extracts from it may be printed or otherwise reproduced without his/her permission.
L'auteur a accordé une licence irrévocsable et non exclusive permettant à la Bibliothèque nationale du Canada de reproduire, prêter. distribuer ou vendre des copies de sa thèse de quelque manière et sous quelque forme que ce soit pour mettre des exemplaires de cette thèse à la disposition des personnes intéressées.

L'auteur conserve la propriélé du droit d'auteur qui protège sa thèse. Ni la thèse ni des extraits substantiels de celle-ci ne doivent être imprimés ou autrement reproduits sans son autorisation. 


\section{ABSTRACT}

A series of freshwater ice indentation experiments were performed with stiff vertical and downward-breaking inclined indentors in the ice tank at the linstitute for Marine Dynamics in the fall of 1989. Indentor width, indentor angle, indentor vclocity and ice sheet thickness were varied for a total of 9.4 tests. Three forces, one moment, three accelerations, indentor displacement, and carriage speed were measured. High sampling rates were used to capture the dynamics of the indentor response. Crushed ice extruded in front of the indentor was collected and sieved whenever possible.

Failure modes of crushing, radial cracking, circumferential cracking, spalling and in-plane cleavage were all observed during vertical indentation. The maximum force on the structure was $29.1 \mathrm{kN}$. Analysis of peak pressures revealed good agreement with data collected by previous researchers. Peak pressures (averaged over the indentor area) ranged from 4 to 11 MPa. A slight decrease in peak pressures with increasing aspect ratio was observed. The small range of contact areas used in the test series produced no evidence of a pressure-area relationship. Peak pressure increased slightly with velocity, up to speeds of $50 \mathrm{~mm} / \mathrm{s}$. At velocities higher than $50 \mathrm{~mm} / \mathrm{s}$ the indentor began to vibrate steadily and peak pressures dipped slightly. Significant vibrations were induced in the structure by crushing failure of the ice. Crushing frequency varied proportionately with velocity at low velocities. At velocities above $50 \mathrm{~mm} / \mathrm{s}$ the response becarre locked at the natural frequency of the structure. An unusual "double-beat" force-time trace was sometimes observed during this locked-in response, and spectral analysis of the signal revealed the emergence of a higher second frequency in the vibration of the structure. 
For the inclined indentation tests, mixed failure modes of crushing and flexural failure were observed. For low indentor angles, crushing dominated. For high indentor angles flexural failure dominated, with crushing still occusring during m. ny tests. Flexural failure was characterized by the formation of a principal circumferential crack and one or two "subsidiary" circumferential cracks. The formation of these subsidiary cracks was due to high in-plane forces combined with vertical deflection of the ice sheet to produce shear and buckling failure. The failure mode underweut transition from bending to crushing as velocity increased, ice thickness increased, and indentor angle decreased. The maximum horizontal force on the structure was $32.7 \mathrm{kN}$, produced with a $10^{\circ}$ indentor while crushing failure was occurring. The normalized peak horizontal force exerted on the inclined indentors increased as the indentor approached vertical. The broken ice pieces produced by flexural failure were between $5 \%$ and $40 \%$ of the characteristic length of the ice shect. The dynamic effect of decreasing broken piece size with increasing velocity was not clearly demonstrated. 


\section{ACKNOWLEDGEMENTS}

Completion of this research would not have been possible without the help of numerous people. Dr. Ian Jordaan provided much-needed advice and guidance throughout my graduate studies. The experiments described in this thesis could not have been conducted without the help of Dr. Stephen J. Jones of the Institute for Marine Dynamics (IMD), the technical staff of the IMD ice tank (esperially Mr. Spence Butt), Dr. Garry Timco of the National Research Council (NlRC) in Ottawa, and Mr. Barry Stone and Dr. Richard MeKenna of the Faculty of Engineering. Fellow graduate students who helped with the experiments and also provided advice include Sanjay Singh, Kurt Kennedy, Shawn Kenny, Jing Xiao, Rick Meaney, Brian Veitch, John Cross, Alfred Marshall, Amgad Hlussein and Roland Baker. Dr. A.S.J. Swamidas' helpful comments were also greatly appreciated. The Faculty of Engineering's Technical Services division const ructed the indentors used in the experiments. Finally, I would like to thank my parents for their years of support and patience, of which any description would be grossly understated.

I am extremely grateful for the personal financial aid provided during the course of my graduate studies by the Department of Career Development and the National Science and Engineering Research Council (NSERC). Funding for the test series was provided through the NSERC Strategic Grant "Ice-Induced Vibrations in Structures". 


\section{Contents}

List of Figures viii

List of Tables $\quad$ xii

List of Symbols xiii

1 INTRODUCTION 1

2 LITERATURE REVIEW

2.1 Introduction $\ldots \ldots \ldots \ldots \ldots \ldots \ldots \ldots \ldots \ldots$

2.2 Vertical structures in ice $\ldots \ldots \ldots \ldots \ldots \ldots$

2.3 Inclined structures in ice $\ldots \ldots \ldots \ldots \ldots \ldots \ldots$

3 EXPERIMENTAL WORK 20

3.1 Test Facility . . . . . . . . . . . . . . . 20

3.2 Instrumentation and Data Acquisition $\ldots \ldots \ldots \ldots 21$

3.3 Experimental procedure $\ldots \ldots \ldots \ldots \ldots \ldots \ldots \ldots \ldots$

3.4 Ice properties $\ldots \ldots \ldots \ldots \ldots \ldots \ldots \ldots \ldots \ldots \ldots \ldots$ 
4.1 Failure modes . . . . . . . . . . . . . . . . . . 31

4.1.1 Brittle failure .................. $33^{4}$

4.1.2 Ductile failure .................. 355

4.2 Peak pressures. ......................... 3s

4.2 .1 Aspect ratio effect ..................... 39

4.2 .2 Velocity effect $\ldots \ldots \ldots \ldots$

4.2.3 Contact area effect ................. 41

4.3 Dynamics ............................ 45

4.3.1 Characteristic failure frequency ........... 45

4.3 .2 Darnage length ................ 53

4.3.3 Higher frequency observations ............ 55

$\$ 4$ Sieve analysis ..................... 56

5 RESULTS AND ANALYSIS: INCLINED INDENTORS 60

5.1 Failure modes . . . . . . . . . . . . . . . . . . 60

5.2 Peal horizontal forces .................. 69

5.2 .1 Indentor angle effect $\ldots \ldots \ldots 70$

5.2 .2 Velocity effect ................... 71

5.3 Dynamics ............................ 72

6 CONCLUSIONS $\quad 76$ 
A VERTICAL INDENTATION DATA

B INCLINED INDENTATION DATA 


\section{List of Figures}

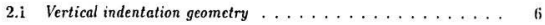

2.2 Cyclic ice crushing process far a vertical indentor ....... 6

2.3 Ice failure modes during vertical edge-indentation (after Timco, 1986) 8

2.4 Deformation-mode map of ice failure showing dominant failure modes at various aspect ratios and strain rates (after Timro, 1986) . . .

2.5 Idealization of force-time histories for four modes of struclural response: (a) creep mode; (b) intermittent crushing; (c) continuous crushing; (d) continuous crushing at high velocity (afıer Kärnä and

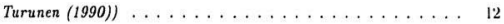

2.6 Idealized internction between an inclined structure and edge-loaded ice sheet $\ldots \ldots \ldots \ldots \ldots \ldots \ldots \ldots \ldots \ldots \ldots$

3.1 Test arrangement ... . . . . . . . . . 23

3.2 Vertical section of $40 \mathrm{~mm}$ ice sheet (Fresh5) . . . . . . . 28

3.3 Horizontal section of $40 \mathrm{~mm}$ ice sheet (Fresh.5) . . . . . . 29 
4.1 Typical force-tine histories for tesis with brittle failure: a) sawtooth; b) harmonic; c) "double-beat" (Test Fresh6_HL_Run2) . . . 33

4.2 Microcracking activily during indentation, including networks and associated microcracking at low veiocities . . . . . . . . . .

4.3 Top: Vertical thin section with in-plane cleavage crack; Bottom: Horizontal thin section with damage to parent ice sheet . . . . . 36

4.4 Typical force-time traces from slow speed tests (Top: $2 \mathrm{~mm} / \mathrm{s}$; Bottom: $0.2 \mathrm{~mm} / \mathrm{s}) \ldots \ldots \ldots \ldots \ldots \ldots \ldots \ldots \ldots$

4.5 IIustration of ice extruded from indentor-ice interface during slow speed tests $(2$ and $0.2 \mathrm{~mm} / \mathrm{s}) \ldots \ldots \ldots \ldots \ldots$

4.6 Peak pressure us. aspect ratio $(D / h)$, including previous work (Nakazava and Sodhi, 1990; Timco, 1986; Michel and Blanchet, 1983; Zabilansky et al., 1975). . . . . . . . . . . .

4.7 Penk pressure us. indentation rate (V/2D), including previous work (Nakazawa and Sodhi, 1990; Timco, 1986; Michel and Blanchet,

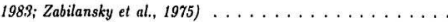

4.8 Peak pressure us. contact area, including previous work (Nakazawa and Sodhi, 1990; Timco, 1986; Michel and Blanchet, 1983; Zabi-

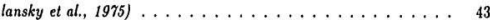

4.9 Peak pressure ts. contact area, present study alone . . . . . . 44

4.10 Typical power spectrum of $F_{x}$ time series $\ldots \ldots \ldots \ldots \ldots$ 
4.11 Portions of $F_{x}$ and $M_{y}$ from test Fresh6_HI.Run2 $(50 m$, s) ... it

4.12 Power spectra of $F_{x}$ and $M_{y}$ from test Fresh6_HI_Run₹ $(50 \mathrm{~mm} / \mathrm{s}) \quad-1 \mathrm{~s}$

4.13 Normalized failure frequency vs. aspect matio . . . . . . . . . 41

4.14 Normalized failure frequency vs. velocity . . . . . . . . . . . 49

4.15 Indentor response at velocities of $50 \mathrm{~mm} / \mathrm{s}, 100 \mathrm{~mm} / \mathrm{s}, 200 \mathrm{~mm} / \mathrm{s}$ and $400 \mathrm{~mm} / \mathrm{s} \ldots \ldots \ldots \ldots \ldots \ldots$

4.16 Damage length to ice thickness ratio vs. aspect ratio . . . . . . 54

4.17 Damage length to ice thickness ratio vs. velocity . . . . . . . 55

4.18 Portion of $F_{x}$ time series with double beat pattern . . . . . 57

4.19 Power spectrum of double beat time series, showing two distinct frequencies...................... 57

4.20 Sieve analysis results: percentage passed us. sicve size . . . . . . 58

5.1 Typical force-time histories from inclined indentation tests: $n$; continuous crushing; b) mixed crushing and fextic; c) pure flcxure . 62

5.2 Portion of $F_{x}$ series from test Fresh5_LO.Run2 featuring formation of principal and "subsidiary" circumferential cracks . . . . . . 64

5.3 Illustration of failure sequence for time series of Figure 5.2 . . . 64

5.4 Failure mode map for tests with inclined indentors . . . . . . 68

5.5 Normalized peak horizontal force $v$ s. indentor angle ... . . . 70

5.6 Normalized peak horizontal force is. indentor velocity . . . . . 72

5.7 Single icebreaking frequency vs. velocity . . . . . . . . . 73 


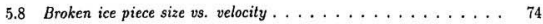

5.9 Ratio of broken ice piece size to characteristic length us, velocity . 75 


\section{List of Tables}

3.1 Summary of tests conducted with vertical indentors . . . . . . 26

3.2 Summar $r_{i}$ of tests conducted with inclined indentors . . . . . . 27

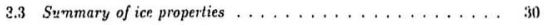




\section{List of Symbols}

$\alpha \quad$ indentor angle from vertical

$\phi \quad$ indentor-ice friction angle

$\rho \quad$ ice density

$\sigma_{f}$ flexural strength of ice

$\zeta \quad$ structural damping

A apparent contact area

$a_{C}$ acceleration of the carriage

$a_{t}$ acceleration of the structure at the indentor

$a_{T F}$ acceleration of the structure at the test frame

$D$ indentor width

E elastic modulus of ice

$F_{x}$ horizontal force on indentor face

$F_{\nu} \quad$ horizontal force on indentor side

$F_{z} \quad$ vertical force on indentor face 


$\begin{array}{ll}f & \text { charac ristic failure frequency } \\ f_{n} & \text { structure natural frequency } \\ H & \text { normalized peak horizontal force } \\ h & \text { ice thickness } \\ K & \text { stiffness of the structure } \\ K_{I} & \text { stiffness of the ice sheet } \\ L_{c} & \text { characteristic length of ice sheet } \\ l & \text { damage length } \\ M_{y} \quad \text { moment due to } F_{x} \\ P_{\text {peak }} \quad \text { peak horizontal pressure } \\ u \quad \text { indentor displacement with respect to carriage } \\ V \quad \text { indentor velocity }\end{array}$




\section{Chapter 1}

\section{INTRODUCTION}

The design of many engineering structures intended for operation in Canada's offshore or inland waterways is complicated significantly by the presence of ice. Canada's East and North Coasts and thousands of rivers and lakes become icebound for a major part of the year, and ice-going vessels, fixed and floating offshore oil and gas platforms, lighthouses, bridges and other marine structures must be built to withstand the rigours of this environment. With increasing exploration and development of natural resources in the Canadian Arctic and off the eastern seaboard, the amount of research on ice-related engineering problems has grown proportionately. Recently, the problem of structural vibration caused by cyclic ice failure processes (particularly crushing) has come under particular scrutiny. These vibrations can lead to structural fatigue and failure; instigate the liquefaction and failure of a fixed structure's soil foundation; induce superstructure motions capable of impeding operation of drilling derricks and other equipment; and cause severe discomfort for crew-members and passengers of ice-going vessels. In March of 1986 an ice-structure interaction featuring periodic crushing around the caisson- 
retained driling structure MOLIKPAQ in the Beaufort Sea threatened the safety of the rig and forced evacuation. The magnitude of the forces exerted on the structure was not threatening, but the periodic nature of the crushing event caused partial liquefaction of the structure's sand core. This event revealed that the dynamic nature of ice crushing activity can pose a serious problem for offshore structures and must be taken into account when designing these structures.

The purpose of the present research is to study the dynamic behaviour of structures during freshwater ice indentation. Specifically, to enable morc accurate prediction of the forces exerted on a structure and the response of a structure subjected to this type of loading. To accomplish this, a scries of tests were performed in the ice tank of the Institute for Marine Dynamics in St. John's, Newfoundland. The test programme was divided into two areas: vertical indentation and inclined indentation. Three vertical indentors of different widths, and four downward-breaking inclined indentors of varying slope were used in the tests for the following purposes:

1. to examine the effects of velocity and aspect ratio (the ratio of structure width to ice thickness) on ice forces and failure mode during vertical indentation.

2. to examine the effects of velocity and aspect ratio on the crushing failure frequency of the ice sheet and the response of the structure during vertical indentation.

3. to examine the effects of velocity and indentor angle on ice forces and failure mode (particularly the transition from flexural to crushing failure) during inclined indentation.

4. to examine the effects of velocity and indentor angle on the sizc of the broken ice pieces created by flexural failure during inclined indentation.

5. to examine the effects of velocity, indentor angle and ice thickness on the failure frequency of the ice sheet during inclined indentation. 
The thesis is divided into four main sections. A review of the literature relevant to small scale vertical and inclined indentation and associated dynamics will be followed by a detailed description of the experimental work performed. The presentation of results and subsequent analysis for vertical and inclined indentation will be done in two separate sections. 


\section{Chapter 2}

\section{LITERATURE REVIEW}

\subsection{Introduction}

Ice bohaves as a visco-elastic material when its interaction with a structure takes place at low relative velocities: the energy of interaction is dissipated by creep mechanisms such as grain-boundary sliding and the movement of dislocations within a single ice crystal. At higher relative velocities the ice behaves as a brittle material, breaking into discrete pieces during interaction with the structure. The size of these discrete pieces can vary from fractions of a millimeter to kilometers, depending on the interaction velocity, geometry and ice properties. The way the ice breaks is described by a particular failure mode such as crushing, buckling or bending. More importantly, the force required to brcak the ice can vary considerably, depe.. ling on the mode of ice failure. This review focusses on the interaction of ice with vertical and inclined structures in the brittle failure regime. 


\subsection{Vertical structures in ice}

The failure mode of ice encountering an advancing vertical structure in a brittle indentation mode has been investigated by many researchers. The gédinetry of vertical indentation is shown in Figure 2.1. For static design purposes, the peak pressure exerted on a structure during indentation is of most importance. This pressure is directly related to the ice failure mode, which in turn is dependent on indentation velocity $(V)$, aspect ratio $(D / h)$, the ice-structure friction angle $(\phi)$, the degree of contact between structure and ice, and the size of the structure and ice. For a narrow vertical structure in contact with a confined ice mass, crushing is the dominant failure mode in brittle indentation. Crushing can occur by itself or with other failure mechanisms, and is the failure mode responsible for exciting a large structural response during dynamic interactions. The following description of the ice crushing process, illustrated in Figure 2.2, is based on the work of Jordaan and Timco (1988). When contact occurs and a force is developed at the ice-structure interface, the structure deflects elastically and the ice viscoelastically. Energy is stored in both the structure and ice. Microcracking begins in the grain boundaries and within grsins of the ice. These cracks grow and finally coalesce, instantaneously forming a thin layer of small crushed ice particles immediately in front of the structure. Upon crushing, the structure and parent ice sheet rebound and squeeze out the mass of crushed ice in a rapid extrusion process. As the crushed ice is cleared from the ice-structure interface, a thin layer of particles may be sintered together by the frictional melting and high local pressures of extrusion, presenting a porous, fused ice mass to the advancing indentor. At some point the structure once again encounters a "solid", albeit damaged, ice mass and the cycle begins again. The "solid" ice sheet in this case is not a virgin 
undamaged ice sleet, but a highly-damaged mass of ice which may behave as a viscous material.

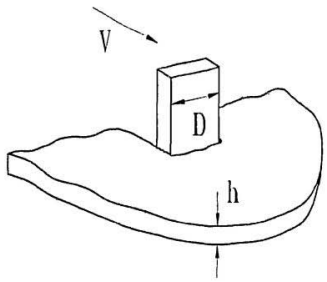

Figure 2.1: Vertical indentation geometry
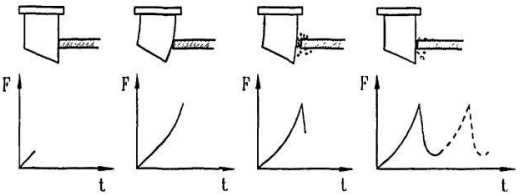

Figure 2.2: Cyclic ice crushing process for a vertical indentor

Timco (1996) conducted a series of freshwater indentation tests in the brittle mode with flat vertical indentors and identified five main failure modes, four of 
which include crushing as one of the primary failure mechanisms:

1. Pure crushing - The ice directly in front of the indentor is broken into a mass of fine discrete particles. There is little or no radial cracking, but the intact ice beyond the crushed region is damaged by microcracking. This failure mode dominates when the ice is highly confined, i.e. at low aspect ratios.

2. Crushing with spalling - In addition to crushing, large chips are broken off the surface of the ice sheet immediately in front of the indentor.

3. Crushing with radial cracking - In addition to crushing, large radial cracks emanate from the indentor into the intact ice sheet.

4. Crushing with radial and circumferential cracking - In addition to crushing and radial cracking, circumferential cracks form at some distance from the indentor due to flexural stresses placed on the ice. Roughly triangular broken ice pieces are formed by the radial and circumferential cracks.

5. Radial and circumferential cracking with buckling - At lower velocities, negligible amounts of crushing occur and the ice fails in buckling, resulting in the formation of radial and circumferential cracks.

Any of these failure modes can dominate under specific indentation conditions. Nakazawa and Sodhi (1990) recently conducted a series of flat vertical freshwater indentation tests and observed similar failure modes. Another failure mode, observed by Michel and Blanchet (1983) and Nakazawa and Sodhi (1990) is that of cleavage. In this mode, a large semi-circular crack is formed immediately in front of the indentor in the plane of the ice sheet. This type of failure may occur occasionally, but cannot be considered a continuous failure mode. The five primary failure modes, and cleavage, are illustrated in Figure 2.3.

A useful representation of the variation in failure mode with indentation parameters is a deformation-mode map, which shows the type of ice failure as a function of indentation rate and aspect ratio. For any single indentation test, the interaction velocity and aspect ratio are usually held constant. For a series of 


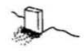

PURE CRUSHING

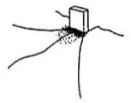

CRUSHING FITI RADIAL CRACKING

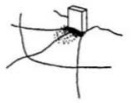

CRUSHING WITH

RADIAL AND

CIRCUMFERENTIAL

CRACKING

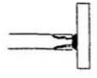

CRUSHING FITH SPALLING

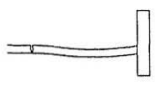

BUCKLING

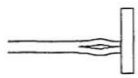

CLEAPAGE

Figure 2.3: Ice failure modes during verlical edgc-indentation (afler Timco, 1986) 
tests, velocity and aspect ratio can be varied over a considerable range of values to derive a deformation-node map such as that seen in Figure 2.4 (after Timco, 1986).

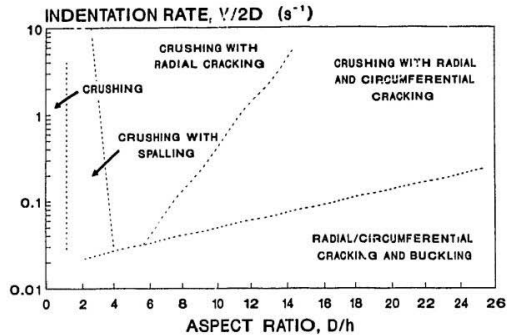

Figure 2.4: Deformation-mode map of ice failure showing dominant failure modes at tarious aspect ratios and strain rates (after Timco, 1986)

Timco compared his results with those of Zablinsky et al. (1975), Hirayama ct al. (1974) and Michel and Blanchet (1983), who all conducted similar experiments. For all the tests, it was found peak pressure (averaged over indentor area) decreased with increasing aspect ratio from about $14 \mathrm{MPa}$ at $D / h=0.4$ to about $2 \mathrm{MPa}$ at $\mathrm{D} / \mathrm{h}=80$. Peak pressure decreased slightly with increasing contact area $(A=D h)$, from about $8 M P a$ at $A \approx 2 \mathrm{~cm}^{2}$ to about $6 M P a$ at $A \approx 200 \mathrm{~cm}^{2}$. This trend of decreasing pressure with increasing contact area was not found by Nakazawd and Sodhi (1990), probably due to the limited variation in contact area 
for their experiments.

The peak pressure exerted on the structure can be dependent on interat tion velocity. Peak pressure increases almost linearly with velocity in the ductile regime, reaches a peak during the transition from ductile to brittle failure and then drops slightly to a value which remains relatively constant as velocity increases throughout the brittle failure regime. Timco (1986) found a slight decrease in peak pressure with increasing velocity, while Nakazawa and Sodhi (1990) report an increase in maximum peak pressure with increasing velocity.

Design for dynamic loading of structures in ice requires knowledge of not. only the magnitude of the ice force, but the variation in force with time. Structures have generally been categorized as either rigid or flexible in the past, but a strict definition for a flexible structure does not exist. No structure is perfectly rigid, but. some can be considered very stiff when compared to the stiffness of the ice shect. The flexibility of the structure can have a significant efiect on the structure's response and the determination of the response force of the structure. Frederking and Timco (1987) report significant magnification of forces between the point of application (indentor face) and the foundation for "flexible" structures, while "rigid" structures do not exhibit this magnification. There are two predominant explanations of ice-induced vibrations found in the literature: the tendency of ice to crush into particles of a certain size, and the "negative damping" (or selfexcited) model for flexible structures proposed by Blenkarn (1970) and refined by Määttänen (1978) and others. Both will be reviewed here.

Peyton (1968) studied the oscillatory nature of ice forces on oil drilling platforms in Cook Inlet, Alaska. He observed a cyclic, ratcheting ice failure at a frequency of about $1 \mathrm{~Hz}$, which was also the natural frequency of the test platform. After conducting further tests in a laboratory environment where the ice 
failure frequency remained at $5 \mathrm{~Hz}$ despite variations in the structure's natural frequency, he concluded that the failure frequency was a basic property of the ice only, known as the "characteristic failure frequency". Peyton also found that the maximum ice forces and the ice compressive strength decreased with increasing velocity. Neill (1976) stated that the ice tends to break into pieces of a certain size, and this size distribution at a particular velocity produces a characteristic frequency spectrum. This may be true when large ice fragments are created, such as in spalling, but the size of the fine particles rroduced by crushing are unlikely to be directly reflected in the failure frequency.

The average length of ice crushed per cycle, called the "damage length" $l$, is often found as the ratio of the velocity to the dominant failure frequency:

$$
l=\frac{V}{f}
$$

This formulation assumes that the distance travelled by the indentor between failure peaks is equal to tiza length of ice crush $-d$ in every cycle, and that all the crushed material is ejected from the ice-structure interface. In reality, a portion of the length of crushed ice may be sintered together at the end of the extrusion cycle to form a highly viscous mass between the indentor and the original "intact" ice. Michel (1978) found from his experiments that the damage length was between $25 \%$ and $50 \%$ of the ice thickness $(0.25 h$ to $0.5 h)$. Sodhi and Morris (1986) conducted indentation experiments in urea-doped ice and used spectral analysis of the force-time records to determine the characteristic crushing frequency. They found that this frequency increased linearly with respect to the ratio of velocity to ice thickness, and the typical damage length was between $0.2 h$ and $0.5 h$. The shape and the size of the crushed layer depends on the degree of confinement at the ice-structure interface (Singh, 1990). The flexibility of the structure also has an 
important effect on the thickness of the crushed layer. A highly flexible structure will store more elastic energy (subsequently released when the ice fails) and creatc a thicker crushed layer than a geometrically similar and stiffer structure.
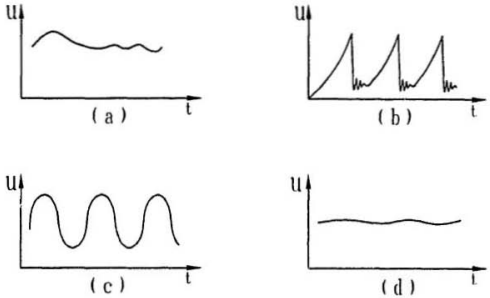

Figure 2.5: Idealization of force-time histories for four modes of struclural response: (a) creep mode; (b) intermittent crushing; (c) continuous crushing; (d) continuous crushing at high velocity (after Kärnä and Turunen (1990))

Toyama et al. (1983) performed a series of indentation tests by forcing saline ice sheets against single- and double-pile configurations with variable natural frequencies. They found that the crushing frequency increased with velocity until it reached the natural frequency of the structure. At this point the crushing frequency (and structural vibrations) remained at the natural frequency despite further increases in velocity. This phenomenon became known as "lock-in". Tsuchiya et al. (1985), Singh et al. (1990) and Kärnä and Turunen (1990) also observed the same lock-in behaviour. Kärnă and Turunen summarized the four observed modes of structural response to ice loading and discussed the lock-in phenomenon 
in detail. At extremely low velocities where creep behaviour dominates, a constant structural deflection occurs, such as shown in Figure 2.5(a). When velocity increases such that ice fails in the brittle regime, the structure usually oscillates in a sawtooth-type manner due to intermittent crushing (Figure 2.5(b)). When the interaction velocity is high enough to induce locking-in of the ice crushing frequency at the natural frequency of the structure, the structural response is a steady harmonic vibration (Figure 2.5(c)). For extremely high ice velocities the structure can no longer respond at the exciting frequency at which the ice crushes, and breaks out of the lock-in phenomenon. The response amplitude decreases significantly to an almost constant deflection (Figure 2.5(d)) caused by the average icc load. This final response mode has been achicved rarely in experimental work, and Sodhi (1989) has published the only evidence of it to date. Kärnä and Turunen developed a model incorporating the crushing and clearing theory of Jordaan and Timco (1988) which correctly predicts these response modes for interactions dominated by the crushing mode of failure.

The negative damping or self-excited theory was first proposed by Blenkarn (1970) after studying extensive ice force data acquired on platforms in Cook Inlet, Alaska. He noted that the measured ice forces were random in nature, while the structure responded at its natural frequency in a periodic manner. This led him to believe that this dynamic response was due to structural characteristics as well as ice properties, i.e. structural vibrations were self-excited. Like Peyton, he noted that the ice compressive strength decreased with increased loading rate and used the concept of negative damping in a single-degree-of-freedom model of the structure's behaviour. Negative apparent damping dictates that the aniplitude of structural oscillations becomes progressively higher in a particular velocity range. As velocity increases the damping becomes positive and the vibration amplitude 
reaches a limit (Frederking, 1989). Mäăttänen (1978) extended the self-excited model to a multi degree of freedom system capable of predicting saw-tooth forcetime histories and their frequencies at low velocities. Other researchers (Eranti et al., 1981; Toyama et al., 1983; Daoud and Lee, 1986) have also developed refinements and variations of the self-excited model. Sodhi (1988) summarized a number of objections to the self-excited model. The self-excited model assumes the excitation force induced by ice failure to be dependent only on the relative velocity between the structure and ice, ignoring the effects of relative displacement, timedependence, changing contact area and damage beyond the crushed layer. The excitation force in the brittle failure mode is especially dependent on these other factors ignored by the self-excited model. Another objection, raised by Singh et al. (1990), is that the negative damping model ignores the large damping of structural oscillations by the presence of the crushed ice material at the icestructure interface. The clearing of the crushed material, an important part. of the overall indentation process, is not included in the model.

\subsection{Inclined structures in ice}

When an inclined structure comes into contact with a confined ice mass, a new failure mode (flexure) can occur which changes the ice-structure interaction. The loads on a structure encountering flexural failure are much lower than those experienced from crushing failure.

The following description of the interaction between a downward-breaking inclined indentor and a level ice sheet is based on Sørensen (1977) and Jebaraj et al. (1990). As the sloping surface of the indentor contacts the edge of the ice sheet local crushing and extrusion occur at the ice-structure interface in a cyclic 
fashion as for a vertical indentor (see Figure 2.6). With each crushing and clearing cycle, however, the apparent contact area increases and the resulting force-time sawtooth pattern will exhibit larger successive peaks. At the same time as this local crushing occurs, the ice sheet is being forced downwards by the structure and flexural stresses are induced in the ice at some distance from the ice-structure interface. Radial cracks sometimes form in the ice sheet, usually emanating from the corners of the indentor. When the flexural stress in the ice sheet exceeds the strength of the ice, a circumferential crack forms at a finite distance from the structure and the force on the structure drops to that required to clear the broken ice pieces. When the structure again reaches the edge of the ice sheet, the cycle repeats. Flexural failure results in the formation of a small number of large broken ice pieces compared to crushing failure where an extremely large number of tiny particles are formed. The flexural failure process exerts smaller forces on the structure than crushing failure.

Most experimental work on inclined structures has been conducted on cones, either upward-or downward-breaking (eg. Hirayama and Obara, 1986). Experiments with flat indentors have included Zabilansky et al. (1975), Sørensen (1977), Haynes et al. (1983), Timco (1984), Frederking and Timco (1985), Michel and Picard (1987) and Valanto (1989). The primary focus in this review will be on the effects of indentor angle $(\alpha)$, ice thickness $(h)$ and velocity $(V)$ on the peak horizontal force and broken ice piece size.

The peak horizontal force is usually normalized with respect to the flexural strength of the ice $\left(\sigma_{f}\right)$ and the square of the thickness $(h)$ to obtain the normalized peak horizontal force, $H$ : 

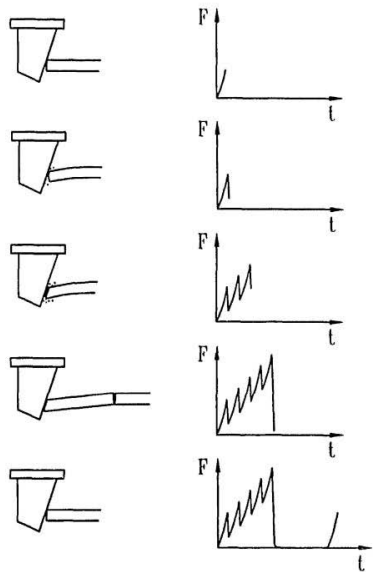

Figure 2.6: Idealized interaction betwcen an inclined structure and edge-loaded ice sheet 


$$
H=\frac{F_{x_{\text {peak }}}}{\sigma_{f} h^{2}}
$$

Haynes et al. (1983) used narrow indentors and varied velocity from $0-100 \mathrm{~mm} / \mathrm{s}$. They found that the normalized horizontal force $H$ was dependent on indentor angle, increasing dramatically as indentor angle decreased below $20^{\circ}$ from the vertical. Hirayama and Obara (1986), summarizing data from several experiments with cones, observed the same dramatic increase in $H$ at slightly higher angles. The increase in $H$ with decreasing indentor angle is expected as the failure mode changes from flexure to crushing as the structure approaches vertical. Vertical loading is responsible for flexural failure and horizontal loading is responsible for crushing failure. As $\alpha$ decreases the horizontal component of the total load will increase and the vertical component will decrease. If the inclination is sufficiently small, crushing may dominate. Boih Zabilansky $t$ t al. (1975) and Bercha and Danys (1975) (conical indentor) observed the transition ffom flexure to crushing with decreasing indentor angle. Jebaraj et al. (1989) noted that the ice failure mode is also influenced by the thickness of the ice sheet. The thickness of the ice sheet will have a lafge effect on the flexural strength of the ice and consequently how great a load can ve supported before flexural failure occurs. Simply, if the crushing or sheas strength of the ice is less than the flexural strength, the failure mode will likely become dominated by crushing and shear, and $H$ will increase dramatically.

Valanto (1989) examined the dynamic effects of velocity on the failure process using a planar indentor in Wärtsila Arctic Research Centre (WARC) Fine Grain (FG) model ice. As the indentor strikes the ice edge, the sheet is deflected downwards and the water underneath resists this deflection. As the indentor velocity increases, the downward acceleration of the ice sheet increases and the hydrody- 
namic inertia increases, and the load on the indentor increases. Valanto noted that the peak force on the indentor was caused by hydrodynamic inertia at the first impact of the indentor, and that this peak force increased almost linearly with increasing velocity. The failure mode for all Valanto's tests was flexure, and he noted no increase in average force with velocity.

The increase in hydrodynamic resistance with velocity also contributes to the transition from flexure to crushing and the corresponding increase in $H$. Flexural stresses which lead to bending failure in the ice are caused by out-of-plane deflections of the ice sheet. As the vertical load required to deflect the ice sheet increases with velocity, the horizontal component of the total load must correspondingly increase. If this horizontal component exceeds the erushing or shear strength of the ice before the ice can be deflected enough to fail in bending, the failure mode will change from flexure to crushing or shear, and $H$ will correspondingly increase. Lipsett and Gerard (1980) and Haynes et al. (1983) observed transitions in failure mode from flexure to crushing with increases in velocity.

The size of the broken ice pieces created by flexural failure is dictated by the point of circumferential cracking. Frederking and Timco (1985), conducting tests with a $1 \mathrm{~m}$ wide inclined indentor in urea-doped ice, found that the circumferential crack form. it approximately $75 \%$ the characteristic length of the ice. Michel and Picard (1987), conducting tests with 100 to $200 \mathrm{~mm}$ wide inclined indentors in freshwater ice, found breaking lengths between $80 \%$ and $175 \%$ of the characteristic length. Sørensen (1978) and Valanto (1989) examined the dynamic effects of velocity on the length of broken ice piece. The increase in hydrodynamic resistance with velocity effectively increases the stiffness of the ice sheet. Consequently, the radius of circumferential cracking will decrease and smaller broken ice pieces will be produced. Sørensen and Valanto's tests both verified a reduction in broken 
ice piece size with increasing indentor velocity. Sørensen's piece size was usually between $10 \%$ and $30 \%$ of the characteristic length of the ice sheet, but reached as high as $80 \%$.

The most important frequency in the flexural failure process is the "single icebreaking frequency ${ }^{n}$, defined by Ettema and Stern (1989) as the ratio of velocity to the distance travelled between two flexural failure events. Correspondingly, the "single icebreaking period" $(1 / f)$ multiplied by the indentor velocity can be used to estimate the size of the ice pieces broken during flexural failure events. 


\section{Chapter 3}

\section{EXPERIMENTAL WORK}

\subsection{Test Facility}

The experiments were performed in the ice tank of the Institute for Marine Dy. namics (IMD) at St. John's, Newfoundland from September 25 to October 6, 1989. The IMD ice tank is $96 \mathrm{~m}$ long, $12 \mathrm{~m}$ wide and $3 \mathrm{~m}$ deep. Onc end of the tank can be thermally isolated by a large sliding door, producing a bay which is used to house the carriage when no tests are in progress. It also allows test preparation such as indentor changing and transducer mounting to be performed in a comfortable environment. The usable ice sheet grown on the basin is $76 \mathrm{~m}$ long, and extends from the carriage bay to the melting pit at the far end of the tank.

The carriage itself is $15 \mathrm{~m}$ long, $14.2 \mathrm{~m}$ wide, $3.9 \mathrm{~m}$ high and weighs 80 tonnes (Jones, 1987). The carriage is driven along steel rails by either a rack-andpinion drive system or a friction-drive system. Both drives are powered by electric motors. There are two operating regimes. In the high-speed operating range (20 
. $4000 \mathrm{~mm} / \mathrm{s}$ ), the carriage is driven by 4 motors and velocity can be maintained with an accuracy of $0.1 \%$. In the low-speed operating range $(0.2-40 \mathrm{~mm} / \mathrm{s})$, the carriage is driven by 2 motors and velocity can be maintained within $0.5 \%$. Up to eight different speeds can be tested in a single run. Each individual speed, the distance moved at this speed, and the carriage acceleration are programmed into the computer before each rin, and the computer subsequently controls carriage motion during the test. Mounted on the carriage is a test frame which can be raised and lowered to facilitate test preparation and allow precise draft setting for testing. This frame can also be moved laterally to allow testing at the quarter points of the tank width, as well as along the centerline. For this test series all runs were done along the centerline.

\subsection{Instrumentation and Data Acquisition}

Seven indentors were manufactured from $3 / 4^{\prime \prime}$ mild steel: $80 \mathrm{~mm}, 100 \mathrm{~mm}$ and $120 \mathrm{~mm}$ wide vertical indentors and $30^{\circ}, 20^{\circ}, 10^{\circ}$ and $5^{\circ}$ downward-breaking inclined indentors all of $120 \mathrm{~mm}$ width. The vertical indentors can be considered as having $0^{\circ}$ inclination. No special treatment or coating was provided to indentor surfaces. The combinations of indentor width and ice thickness were chosen to generate forces that would approach the design limit of the towing carriage. Since the maximum design carriage load applied at centerline is $60 \mathrm{kN}$, a target force of $40 \mathrm{kN}$ was used, providing a margin of safety.

For each test, the indentor was securely bolted to a $44.5 \mathrm{kN}$ AMTI 6-component load cell which was in turn attached to the towing carriage via a test-frame extension (see Figure 3.1). Only four components were measured for this test series: the horizontal forces ( $F_{x}$ forward, $F_{y}$ sideways), the verticai force $\left(F_{z}\right)$, and 
the moment about the $y$-axis $\left(M_{y}\right)$. Three accelerometers were mounted on the arrangement: one at the indentor just above the waterline (acceleration at the indentor $a_{7}$ ), one at the test frame inmediately above the load cell (acceleration of the test frame $a_{T F}$ ), and onc $\mathrm{s}_{n}$ the main carriage body (acceleration of the carriage $a_{C}$ ). A linear-voltage-displacement-transducer (LVDT) monnted on a separate post on the carriage measured the displacement $u$ of the indentor relative to the carriage. Displacement in the direction of powive $F_{x}$ loading is considered positive. Initially, a string potentiometer ("yo-yo") was mounted on a platform on the ice several meters ahead of the indentor to ni*asure the dis placement of the indentor relative to the fixed ice sheet. Examination of the acquired data revealed that the "yo-yo"'s spring response was not capable of capturing the indentor's oscillations, and the only displacement recorded was that of the carriage. The use of the "yo-yo" was subsequently abandoned.

Tests were performed at eight speeds: $400,200,100,50,20,10,2$ and 0.2 $\mathrm{mm} / \mathrm{s}$. "High-speed" tests $(400-50 \mathrm{~mm} / \mathrm{s}$ ) were sampled at $2000 \mathrm{~Hz}$ and passed through a $1000 \mathrm{~Hz}$ anti-aliasing filter. "Low-speed" tests $(20 \cdot 0.2 \mathrm{~mm} / \mathrm{s})$ were sampled at $200 \mathrm{~Hz}$ and filtered at $100 \mathrm{~Hz}$. This reduction in sampling rate was required because the longer test times associated with the slower speed tests would have produced exorbitantly large data files, filling the acquisition system's available memory before all speeds could be tested. A NEFF System 620 Series 300 signal conditioner provided excitation voltage to all the measuring instrumentation. The resulting analog signals were amplified and digitized by a NEFF System 620 Series 100 amplifier/multiplexer and stored on a VAX 11/750 computer, and a KYOWA RTP-600B 14-channel tape recorder for back-up purposes.

Three video cameras recorded the tests. One was positioned underwater and ahead of the indentor, another filmed the tests from the side of the carriage and 


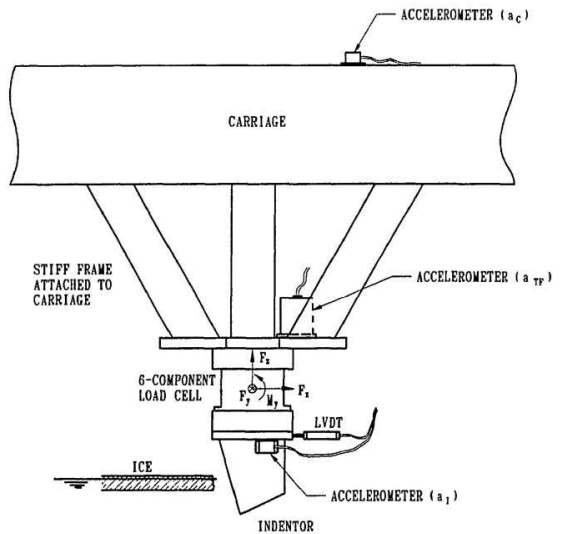

Figure 3.1: Test arrangement 
the final camera filmed from the front of the carriage. For inclined indentor tests a fourth camera filmed the channel behind the indentor to record the size of the broken ice pieces. A still camers was mounted above and in front of the indentor to photograph cracking patterns in the ice sheet illuminated by underwater lighting.

\subsection{Experimental procedure}

An even edge was cut in the ice sheet using a pruning saw and the indentor advanced to the interface. The four "high-speed" $(50-400 \mathrm{~mm} / \mathrm{s})$ tests were run consecutively in order of increasing speed, crushing $2 \mathrm{~m}$ of ice at each velocity. Crushed ice samples were collected for most tests and sieved immediately afterwards to determine the size distribution of the crushed particles.

A new interface was cut and the four "low-speed" $(20-0.2 \mathrm{~mm} / \mathrm{s})$ tests were performed in order of decreasing speed, and when $d r y$ crushed ice was produced it was collected and sieved. For the 20 and $10 \mathrm{~mm} / \mathrm{s}$ tests, a $2 \mathrm{~m}$ length of ice was crushed. The time required to crush $2 \mathrm{~m}$ of ice at both the 2 and $0.2 \mathrm{~mm} / \mathrm{s}$ speeds would have resulted in the saturation of the data acquisition system's storagc capacity before the lowest speed was reached. Consequently, time limits of 400 and 500 seconds (corresponding to ice lengths of $0.8 \mathrm{~m}$ and $0.1 \mathrm{~m}$ ) were placed on the velocities of 2 and $0.2 \mathrm{~mm} / \mathrm{s}$ respectively. A total of 94 successful tests were performed with variations in carriage speed $(V)$, ice thickness $(h)$, indentor width $(D)$ and indentor angle $(\alpha)$. For several attempted tests the carriage was unable to maintain the programmed velocity, and on three occasions was unable to progress through the ice at all. Significant fluctuations in carriage speed occurred for almost all tests at $20 \mathrm{~mm} / \mathrm{s}$ and $10 \mathrm{~mm} / \mathrm{s}$, and the data was not included in the analysis. The low-speed carriage operating system was used for these tcsts, 
and the two drive motors could not maintain steady velocity due to the fluctuating nature of the ice lnad. Table 3.1 (vertical) and Table 3.2 (inclined) provide detailed test matrices.

To determine the natural frequency of the indentor and support structure step unloading, or "plucking", tests were performed with the indentor in air and water. A rope was secured around the indentor, led through a pulley arrangement to the end of the tank and a $200 \mathrm{~kg}$ weight suspended from the end. The rope was suddenly cut, effectively "plucking" the indentor to set it oscillating at its natural frequency. These oscillations were sampled at $2000 \mathrm{~Hz}$, passed through a $1000 \mathrm{~Hz}$ anti-aliasing filter, and recorded for future analysis. The indentor displacement, indentor acceleration and $F_{x}$ signals were subjected to spectral analysis and the natural frequency of the structure, $f_{n}$, was found to be approximately $63 \mathrm{~Hz}$. Structural damping $\zeta$ was $4.6 \%(\zeta=0.046)$, and the stiffness of the structure $K$ was $9.4 \times 10^{8} \mathrm{~N} / \mathrm{m}(9.4 \mathrm{kN} / \mathrm{mm})$.

\subsection{Ice properties}

Six freshwater ice sheets were grown with a wet-seeding process which produces a fine-grained S2, strictly columnar ice. The temperature inside the tank was lowered to $-20^{\circ} \mathrm{C}$, and a mist of warm water droplets sprayed into the air. These droplets freeze and drop to the water surface to produce a fine-grained skim of ice, and these grains act as nuclei for columnar growth. The tank was kept at $-20^{\circ} \mathrm{C}$ until the target ice thickness was reached. Since freshwater ice was user, no warm-up or tempering was required, and the tests were conducted at $-5^{\circ} \mathrm{C}$. After testing, ice samples were immediately taken and stored in IMD's cold room for thin-sectioning. The average grain size was determined from these thin sections 


\begin{tabular}{|c|c|c|c|c|c|c|}
\hline TEST & $\begin{array}{l}\text { Indentivr } \\
\text { wirlth } \\
\text { (min) }\end{array}$ & $\begin{array}{c}\text { Ice } \\
\text { chickness } \\
\text { (mun) }\end{array}$ & $\begin{array}{l}\text { Aspect } \\
\text { ratho } \\
\text { (I)/h) }\end{array}$ & $\begin{array}{c}\text { Test } \\
\text { speed } \\
\text { (mais) }\end{array}$ & $\begin{array}{l}\text { Mean } \\
\text { faree } \\
\text { (kN) }\end{array}$ & $\begin{array}{l}\text { Teak } \\
\text { force } \\
\text { (kN) }\end{array}$ \\
\hline \multirow{5}{*}{$\begin{array}{l}\text { Fresh1-HI-Run2 } \\
\text { Fresh1-LO-Run2 } \\
\text { Fresh1-HI-Run3 } \\
\text { Fresh1-LO-Run3 }\end{array}$} & \multirow[t]{5}{*}{80} & \multirow[t]{5}{*}{27,5} & \multirow[t]{5}{*}{2,78} & 50 & 0.60 & \\
\hline & & & & 10 & 3,50 & $12.8 ! 3$ \\
\hline & & & & 100 & 0,346 & \\
\hline & & & & 2 & 4.28 & 15.43 \\
\hline & & & & 0.2 & $4 . \mathrm{kJ}$ & 12.21 \\
\hline \multirow[t]{4}{*}{ Fresh2-HI-RunI } & \multirow[t]{6}{*}{80} & \multirow[t]{6}{*}{35.9} & \multirow[t]{4}{*}{2.23} & 4100 & 0.61 & \\
\hline & & & & 200 & 0.50 & \\
\hline & & & & 100 & 0.48 & \\
\hline & & & & 50 & 0,08 & \\
\hline \multirow[t]{2}{*}{ Fresh2-LO-Run1 } & & & & 2 & 12.46 & 22.35 \\
\hline & & & & 0.2 & 0.71 & 15.77 \\
\hline \multirow[t]{4}{*}{ Fresh2-HI-Run2 } & \multirow[t]{5}{*}{100} & \multirow[t]{5}{*}{35.9} & \multirow[t]{4}{*}{2.79} & 400 & 0.71 & \\
\hline & & & & 200 & 0.53 & \\
\hline & & & & 100 & 0.13 & \\
\hline & & & & 50 & 1.02 & \\
\hline Fresh2-LO-Run2 & & & & $\begin{array}{c}2 \\
0.2\end{array}$ & $\begin{array}{l}13.42 \\
9.90\end{array}$ & 246,47 \\
\hline \multirow[t]{4}{*}{ Fresh3-HI-Runl } & \multirow[t]{6}{*}{120} & \multirow[t]{6}{*}{20.7} & \multirow[t]{4}{*}{4.49} & 400 & 0.65 & \\
\hline & & & & 200 & 0.50 & \\
\hline & & & & $I[x]$ & 0.17 & \\
\hline & & & & so & 0.85 & \\
\hline \multirow[t]{2}{*}{ Fresiz3-LO-Runl } & & & & 2 & 19.47 & 18.92 \\
\hline & & & & 0.2 & 6.16 & 15,26 \\
\hline \multirow[t]{4}{*}{ Fresh3-III-Run2 } & \multirow[t]{5}{*}{100} & 20,7 & 3.75 & 400 & 0.48 & \\
\hline & & & & 200 & $0.10]$ & \\
\hline & & & & {$[x]$} & 0.35 & \\
\hline & & & & 50 & $0,8-1$ & \\
\hline Fresli3-LO-Run2 & & & & ${ }_{n+2}^{2}$ & $\begin{array}{l}8.98 \\
5.17\end{array}$ & $\begin{array}{l}16.67 \\
12.73\end{array}$ \\
\hline Fresh4-LO-Rund & 80 & 46.3 & 1.73 & 2 & 17.99 & 25.25 \\
\hline & & & & 0.2 & 17.35 & 21.70 \\
\hline Fresh5-III-Run5 & 100 & 35.6 & 2.81 & 400 & 6.71 & 19.75 \\
\hline & & & & 200 & 5.15 & $19 . \pi 4$ \\
\hline & & & & 100 & 5.00 & 20.80 \\
\hline Fresh16-III-Run1 & 80 & 26.2 & 3.05 & 100 & 3.20 & 10.53 \\
\hline & & & & 200 & 3.56 & $13.0 \cdot 1$ \\
\hline & & & & 100 & 2.87 & 11.12 \\
\hline & & & & 50 & 3.18 & 12.58 \\
\hline Fresh6-LO-Run1 & & & & 2 & 7.39 & 13.94i \\
\hline & & & & 0.2 & 2.6.6 & 8.58 \\
\hline Freshit-HI-Run2 & 100 & 26.2 & 3.82 & 400 & 5.68 & 10.46 \\
\hline & & & & 200 & 4.05 & 14.78 \\
\hline & & & & 100 & 3.98 & 12.31 \\
\hline Freats-LOAn? & & & & 50 & 6.44 & 27.08 \\
\hline Fresh6-LO-Kun2 & & & & 2 & 7.75 & 14.38 \\
\hline Fresth-HI-Run3 & 120 & 26.2 & 4.58 & 0.2 & 7.14 & 10.97 \\
\hline Ireshib-111-19uns & 120 & 26.2 & 1.58 & $\begin{array}{l}100 \\
200\end{array}$ & $\begin{array}{l}6.06 \\
4.64\end{array}$ & 15.52 \\
\hline & & & & 100 & 1.32 & 15.51 \\
\hline & & & & 50 & 8.06 & 20.1 .1 \\
\hline Fresh6-LO-Run3 & & & & 2 & 8.09 & 16.32 \\
\hline & & & & 0.2 & 6.77 & 14.65 \\
\hline
\end{tabular}

Table 3.1: Summary of tests conducted with vertical indentors 


\begin{tabular}{|c|c|c|c|c|c|c|c|}
\hline TFST & $\begin{array}{c}\text { Indentor } \\
\text { width } \\
(\mathrm{mm})\end{array}$ & $\begin{array}{c}\text { Indentor } \\
\text { angle } \\
\text { (degrees) }\end{array}$ & $\begin{array}{c}\text { Ice } \\
\text { thickncss } \\
(\mathrm{mm})\end{array}$ & $\begin{array}{c}\text { Test } \\
\text { speed } \\
(\mathrm{mm} / \mathrm{s}) \\
\end{array}$ & $\begin{array}{l}\text { Mean } \\
\text { force } \\
(\mathrm{kN})\end{array}$ & $\begin{array}{l}\text { Pcak } \\
\text { force } \\
(\mathrm{kN})\end{array}$ & $\begin{array}{c}\text { Failure } \\
\text { mode }\end{array}$ \\
\hline \multirow[t]{4}{*}{ Fresh'\}-III-Run3 } & \multirow[t]{5}{*}{120} & \multirow[t]{5}{*}{30} & \multirow[t]{4}{*}{26.7} & 400 & 1.09 & & $\mathrm{C}, \mathrm{F}$ \\
\hline & & & & 200 & 0.84 & & F \\
\hline & & & & 100 & 0.65 & & $\mathrm{~F}$ \\
\hline & & & & 50 & 1.35 & & F \\
\hline Fresh3-LO-Run3 & & & & 10 & 0.60 & 1.88 & F \\
\hline \multirow[t]{4}{*}{ Fresh4-HI-RunI } & \multirow[t]{6}{*}{120} & \multirow[t]{6}{*}{30} & \multirow[t]{6}{*}{46.3} & 400 & 2.99 & 5.07 & C \\
\hline & & & & 200 & 2.50 & 6.03 & $\mathrm{C}$ \\
\hline & & & & 100 & 1.24 & 4.13 & $F, C$ \\
\hline & & & & 50 & 2.39 & 4.77 & C \\
\hline \multirow[t]{2}{*}{ Fresh4-LO-Run1 } & & & & 20 & 0.55 & 4.29 & $\mathrm{~F}$ \\
\hline & & & & 10 & 1.19 & 4.17 & F \\
\hline \multirow[t]{4}{*}{ Frcsh4-III-Run2 } & \multirow[t]{5}{*}{120} & \multirow[t]{5}{*}{20} & \multirow[t]{4}{*}{46.3} & 400 & 4.70 & 8.84 & $\mathrm{C}$ \\
\hline & & & & 200 & 3.89 & 8.40 & C \\
\hline & & & & 100 & 3.90 & 10.04 & C \\
\hline & & & & 50 & 4.61 & 13.61 & $\mathrm{C}$ \\
\hline Fresh4-LO-Run2 & & & & 10 & 1.31 & 0.93 & $F$ \\
\hline \multirow[t]{4}{*}{ Fresh4-HI-Run3 } & \multirow[t]{4}{*}{120} & \multirow[t]{4}{*}{10} & \multirow[t]{4}{*}{46.3} & 400 & 7.88 & 24.11 & $\mathrm{C}$ \\
\hline & & & & 200 & 9.27 & 15.52 & $\mathrm{C}$ \\
\hline & & & & 100 & 13.66 & 32.73 & C \\
\hline & & & & 50 & 13.62 & 27.84 & $\mathrm{C}$ \\
\hline \multirow[t]{4}{*}{ Fresh5-III-RunI } & \multirow[t]{6}{*}{120} & \multirow[t]{6}{*}{30} & \multirow[t]{6}{*}{35.6} & 400 & 1.92 & 4.07 & $\mathrm{C}, \mathrm{F}$ \\
\hline & & & & 200 & 1.08 & 3.96 & F \\
\hline & & & & 100 & 1.07 & 3.06 & $F, C$ \\
\hline & & & & 50 & 1.12 & 2.36 & C \\
\hline \multirow[t]{2}{*}{ Eresh5-LO-Run 1} & & & & 20 & 0.55 & 2.80 & $F, C$ \\
\hline & & & & 10 & 0.33 & 2.89 & $\mathrm{~F}$ \\
\hline \multirow[t]{4}{*}{ Presh5-III-Run2 } & \multirow[t]{6}{*}{120} & 20 & 35.6 & 400 & 1.56 & 5.58 & $\mathrm{~F}$ \\
\hline & & & & 200 & 0.67 & 5.19 & $\mathrm{~F}$ \\
\hline & & & & 100 & 0.15 & 4.56 & F \\
\hline & & & & 50 & 0.31 & 8.06 & $\mathrm{C}$ \\
\hline Fresh5-LO-Run2 & & & & 20 & 0.43 & 5.10 & $\mathrm{~F}$ \\
\hline & & & & 10 & 0.45 & 4.84 & $\mathrm{~F}$ \\
\hline Fresh5-III-Run3 & 120 & 10 & 35.6 & 400 & 7.67 & 19.70 & C \\
\hline & & & & 200 & 6.47 & 10.10 & $\mathrm{C}$ \\
\hline & & & & 100 & 8.10 & 23.70 & $\mathrm{C}$ \\
\hline & & & & 50 & 7.53 & 20.92 & C \\
\hline Fresh5-III-Rund & 120 & 5 & 35.6 & 400 & 6.79 & 21.91 & C \\
\hline & & & & 200 & 5.17 & 20.67 & C \\
\hline & & & & 100 & 3.98 & 13.44 & C \\
\hline & & & & 50 & 12.40 & 27.03 & C \\
\hline Fresh5-LO-Run 4 & & & & 20 & 2.00 & 23.15 & F,C \\
\hline & & & & 10 & 2.24 & 24.14 & $\mathbf{F}, \mathbf{C}$ \\
\hline
\end{tabular}

Table 3.2: Summary of tests conducted with inclined indentors 
using the mean intercept length method (Dieter, 1974) which gives good results for strictly columnar ice (Cole, 1989). This grain size was between $1.35 \mathrm{~mm}$ and $1.64 \mathrm{~mm}$ for all ice sheets. Typical sections are shown in Figures 3.2 and 3.3.

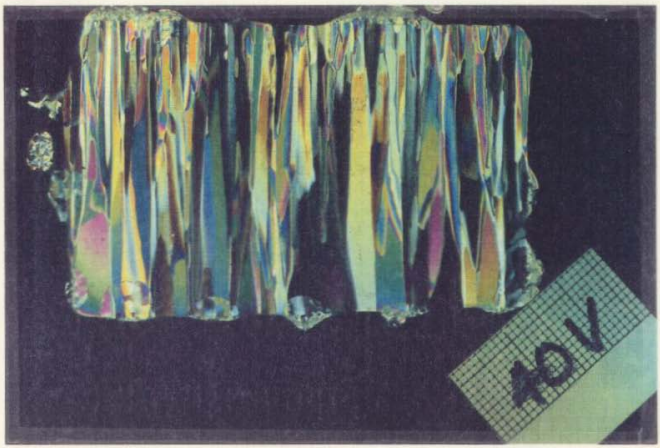

Figure 3.2: Vertical section of $40 \mathrm{~mm}$ ice sheet (Fresh5)

Ice properties were measured before and after testing. The flexural strength $\left(\sigma_{f}\right)$, the elastic modulus $(E)$ and the density $(\rho)$ were tested before the first run of each day. The flexural strength of the ice depends on the direction of loading, and is generally higher when loaded downwards. The flexural strength of the ice was tested in both the downward-breaking and upward-breaking modes. The ice continues to grow slightly during a day of testing, and the ice thickness $(h)$ was measured at different points along the broken channel after each run to record 


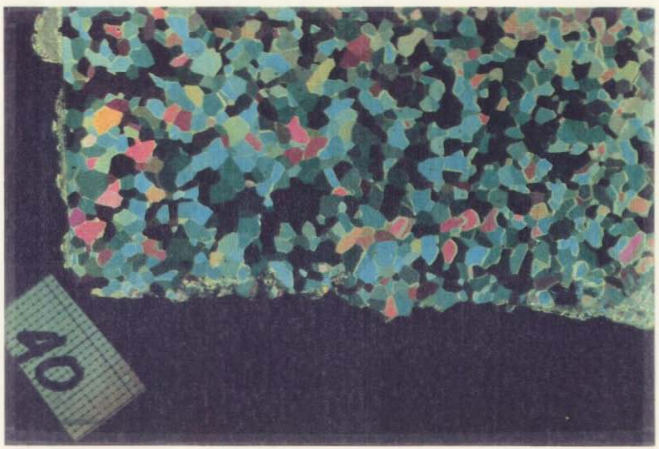

Figure 3.3: Horizontal section of $40 \mathrm{~mm}$ ice sheet (Fresh5) 
variations with respect to tank position and time. A summary of average ice properties measured for each sheet is presented in Table 3.3.

\begin{tabular}{||c|c|c|l|c|c|c|c||}
\hline $\begin{array}{c}\text { Ice } \\
\text { Sheet }\end{array}$ & $\begin{array}{c}h_{\text {NOM }} \\
(\mathrm{mm})\end{array}$ & $\begin{array}{c}h_{\text {AVG }} \\
(\mathrm{mm})\end{array}$ & $\begin{array}{l}\sigma_{f} \\
(\mathrm{kPa})\end{array}$ & $\begin{array}{c}E \\
(\mathrm{MPa})\end{array}$ & $E / \sigma_{S}$ & $\begin{array}{c}L_{c} \\
(\mathrm{~cm})\end{array}$ & $\begin{array}{c}\rho \\
\left(\mathrm{kg} / \mathrm{m}^{3}\right)\end{array}$ \\
\hline \hline Fresh 1 & 30 & 27.5 & $\begin{array}{l}\downarrow 1043.5 \\
\uparrow 996.5\end{array}$ & & & & \\
\hline Fresh 2 & 40 & 35.9 & $\begin{array}{l}\downarrow 902.0 \\
\uparrow 841.5\end{array}$ & 5867.3 & 6664 & 126 & 916 \\
\hline Fresh 3 & 30 & 26.7 & $\begin{array}{l}\downarrow 1048.5 \\
\uparrow 884.7\end{array}$ & 5892.8 & 5261 & 100 & 917 \\
\hline Fresh 4 & 50 & 46.3 & $\begin{array}{l}\lfloor 911.5 \\
\uparrow 682.0\end{array}$ & & & & 918 \\
\hline Fresh 5 & 40 & 35.6 & $\begin{array}{l}\downarrow 927.0 \\
\uparrow 809.5\end{array}$ & 5750.7 & 6270 & 119 & 918 \\
\hline Fresh 6 & 30 & 26.2 & $\begin{array}{l}\lfloor 1005.5 \\
\uparrow 951.0\end{array}$ & 4659.5 & 4561 & 90 & 919 \\
\hline
\end{tabular}

Table 3.3: Summary of ice properties 


\section{Chapter 4}

\section{RESULTS AND ANALYSIS:}

\section{VERTICAL INDENTORS}

\subsection{Failure modes}

Visual records in the form of still photographs and video-tape were used in conjunction with first-hand observations to examine the failure mode of the ice during each test. Particular failure modes also have characteristic force-time records, and examination of these records can help verify the occurrence of a specific type of ice failure. Plots of all data for tests Fresh6.HI_Run2 and Fresh6_LO_Run2 $(D=100 \mathrm{~mm}, h=30 \mathrm{~mm}, V=0.2,2,10,20,50,100,200$ and $400 \mathrm{~mm} / \mathrm{s}$ ) are presented in Appendix A. 


\subsubsection{Brittle failure}

Tests performed at velocities from $10 \mathrm{~mm} / \mathrm{s}$ to $400 \mathrm{~mm} / \mathrm{s}$ induced brittle ice failure. This range corresponds to "strain rates" from $4 \times 10^{-2} s^{-1}$ to $2.5 s^{-1}$. The "strain rate" for vertical edge-indentation has been used by Timco (1986) and others as $(V / 2 D)$ for low aspect ratios (0-5). Other expressions for strain rate include $V / D$ and $V / 4 D$. All these expressions imply that the stress in the ice caused by indentor penetration is distributed through the ice up to a distance of the order of magnitude of the indentor width. Jordaan and Timco (1988), however, have subsequently shown that almost the entire ice strain is absorbed in the crushed layer, and a much smaller length of the ice sheet than $2 D$ should be used to determine the true strain rate. For the purposes of comparison with previously published results, $V / 2 D$ will be retained as a normalized velocity term but will be referred to as "indentation rate".

Examples of force-time traces recorded at different velocities are shown in Figure 4.1. A sawtooth type force trace indicative of intermittent crushing failure was observed at intermediate velocities. A harmonic force-time trace indicative of continuous crushing, and often an unusual "double-beat" force-time trace were observed at high velocities.

The dominant failure mode for all these tests was crushing with radial cracking and spalling. Radial cracks were generally 1 to $2 \mathrm{~m}$ in length, but sometimes extended for meters through the ice. These cracks originated near the corners and the center of the face of the indentor. As the lest speed increased, the length of the radial cracks decreased. When more than one radial crack formed, circumferential cracking sometimes occurred at distances up to $2 \mathrm{~m}$ from the indentor. At intermediate speeds $(10,20,50$ and $100 \mathrm{~mm} / \mathrm{s})$ the crushed ice 

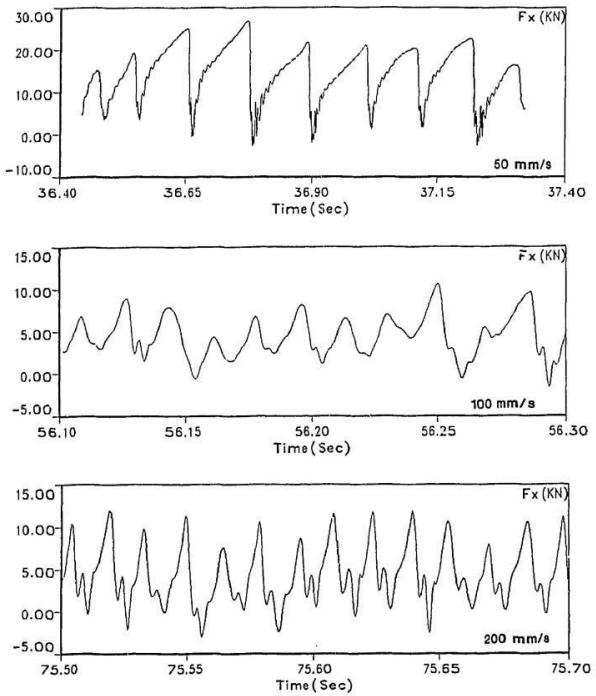

Figure 4.1: Typical force-time histories for tests with brittle failure: a) satooth; b) harmonic; c) "double-beat" (Test Fresh6_HL_Run2) 
was ejected in spurts. For some tests a pronounced banging sound accompanied crushing events. These tests tended to be those in which the highest indentor loads and greatest indentor displacements were observed.

At high speeds (200 and $400 \mathrm{~mm} / \mathrm{s}$ ) crushing usually occurred in a more continuous manner. A steady spray of crushed ice was ejected from the indentorice interface up to $1.5 \mathrm{~m}$ ahead of the indentor. Long radial cracks did not always form. More common was the formation of short $(20$ to $30 \mathrm{~cm}) 45^{\circ}$ radial cracks at both corners of the indentor at regular intervals. Circumferential cracks formed infrequently, and at smaller distances from the indentor face $(<1 \mathrm{~m})$ than for intermediate speed tests.

Extensive microcracking took place in the region immediately in front of the indentor, indicated by the "clouding" of the ice. This region was roughly of semi-circular shape and extended about one indentor width into the parent ice sheet. At slower velocities ( 2 to $50 \mathrm{~mm} / \mathrm{s}$ ), shorter networks of cracks would sometimes emanate from ,oints along the primary radial cracks (see Figure 4.2). Microcracking would occur at the ends of the "branches", although to a much smaller extent than immediately in front of the indentor. There was always a noticeable time gap (of the order of seconds) between the formation of the original large radial crack and the formation of the offshooting networks. The networks did not form at higher velocities (100 to $400 \mathrm{~mm} / \mathrm{s}$ ).

Thin sections of two ice samples taken from in front of the indentor immediately after two different $400 \mathrm{~mm} / \mathrm{s}$ tests are shown in Figure 4.3. The horizontal thin section shows damage to the parent ice sheet caused by stress concentrations at the indentor edge. The resulting structure consists of grains many times smaller than those of the parent ice. The vertical thin section reveals a cleavage crack in the plane of the ice sheet at the end of a test. 


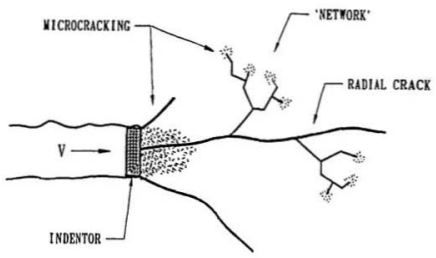

Figure 4.2: Microcracking activity during indentation, including networks and associnted microcracking at low velocities

\subsubsection{Ductile failure}

"Ductile" behaviour was predominant for indentation rates below $1.25 \times 10^{-2} s^{-1}(2$ and $0.2 \mathrm{~mm} / \mathrm{s}$ tests). Although the overall response of the ice at these test speeds can be characterized as "ductile", it must be emphasized that microcracking and larger local fracture damage the ice immediately in front of the indentor, leading to crack-enhanced viscous flow. A briel burst of cracking activity was followed by a long period where the indentor extruded the damaged material from the ice-structure interface in a viscous manner. Typical force-time traces from slower speed tests are shown in Figure 4.4. The rounded peaks of the force-time traces are indicative of ductile failure.

As the indentor progressed into the ice, a large radial crack usually formed at the center of the indentor face and extended up to $2 \mathrm{~m}$ into the parent ice sheet. Occasionally, a second large radial crack formed from the edge of the indentor face. 

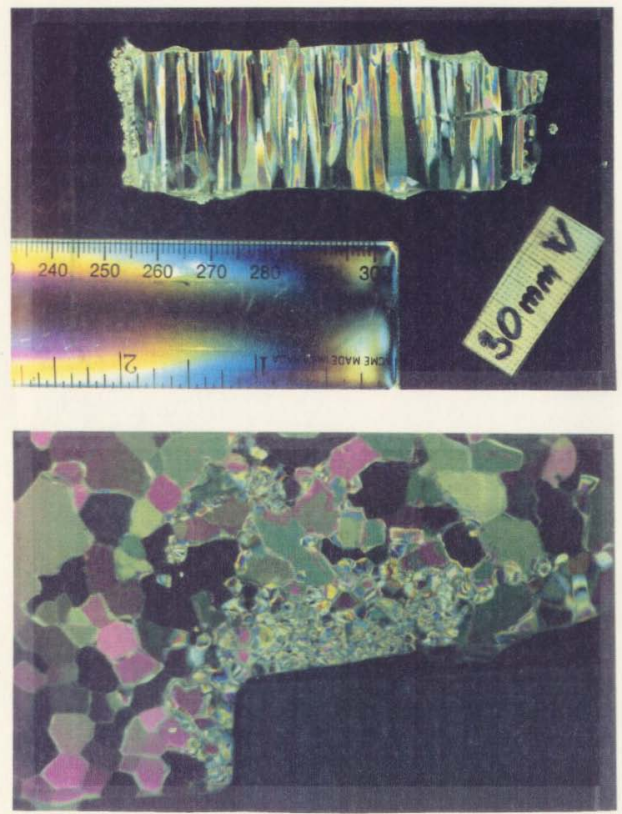

Figure 4.3: Top: Vertical thin section with in-plane cleavage crack; Bottom: Horizontal thin section with damage to parent ice sheet 

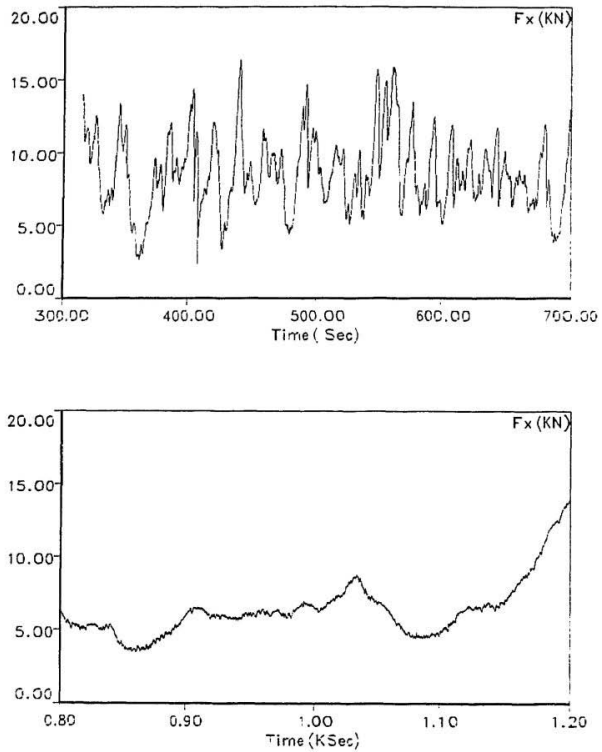

Figure 4.4: Typical force-time traces from slow speed tests (Top: $2 \mathrm{~mm} / \mathrm{s}$; Boltom: $0.2 \mathrm{~mm} / \mathrm{s}$ ) 
The ice sheet was often deflected downwards during these slower tests, flooding up to $0.6 \mathrm{~m}$ in front of the indentor for $2 \mathrm{~mm} / \mathrm{s}$ tests, and up to $2 \mathrm{~m}$ in front of the indentor for $0.2 \mathrm{~mm} / \mathrm{s}$ tests. Buckling was responsible for this flooding. lor some tests 1 or 2 circumferential cracks formed, at distances up to $2 m$ from the indentor face. At the indentor-ice interface, highly-damaged ice "flowed" from the contact region in a generally continuous fashion, accompanied by a high squeaking sound. The ice extruded from the interface was tsually a partially fused "curl" of rod-shaped ice pieces (see Figure 4.5) with a "diameler" of 3 to $7 \mathrm{~mm}$, atid at length roughly the sarne as the indentor width.

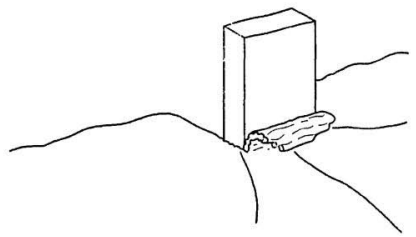

Figure 4.5: Illustration of ice extruded from indentor-ice interface during slow speed tests ( 2 and $0.2 \mathrm{~mm} / \mathrm{s}$ )

\subsection{Peak pressures}

The peak force on the indentor face $\left(F_{x_{\text {peak }}}\right)$ for cach test was found using the DAS_CALC soltware at the IMD. The highest force measured was $29.14 \mathrm{kN}$ for test Fresh6_HI_Run3 at $50 \mathrm{~mm} / \mathrm{s}$. This was a $120 \mathrm{~mm}$ wide vertical indentor in $30 \mathrm{~mm}$ thick ice. Peak pressures were calculated assuming a contact area of $D h$, 
the indentor width times the thickness of the ice sheet, such that:

$$
P_{\text {peak }}=\frac{F_{x_{\text {peok }}}}{D h}
$$

The actual contact area is certain to have varied between this maximum value $(D h)$ and lower values, due to the efiect of spalling at the top and bottom of the ice sheet. Since the collection of spall samples was not continuous, and the actual shape of the contact area at the time the peak force was induced is not known, the apparent contact area $(D h)$ was used to determine peak pressures. The duration of indentation will also have an effect on the peak pressure. Keeping all other test parameters constant, a longer test time is likely to produce a higher peak load than a shorter test. This should be kept in mind when considering the comparisons of the peak pressures reported in the previous literature and the current tests presented in the following sections.

During test series Fresh1_HI, Fresh2_HI and Fresh3_HI, $F_{x}$ was sampled at $2000 \mathrm{~Hz}$ and passed through a $1 \mathrm{~Hz}$ (not $1 \mathrm{kHz}$ as intended) anti-aliasing filter. The peak forces determined from the resulting signal could not be included in the following analyses with confidence, and the data fron the affected tests was not used.

\subsubsection{Aspect ratio effect}

A plot of peak pressure vs, aspect ratio including data from previous similar experiments (vertical indentation, freshwater ice, planar indentor, and aspect ratios between 1 and 5) is shown in Figure 4.6 (Nakazawa and Sodhi, 1990; Timco, 1986; Michel and Blanchet, 1983; Zabilansky et al., 1975). Aspect ratio varied between 1.7 and 4.6 and the structure can be cunsidered narrow. Peak pressures ranged 
from 4 to $11.3 \mathrm{MPa}$, although most were below $8 \mathrm{MPa}$. Peak pressure exhibited a slight decline with increasing aspect ratio. The present results agree with the previous work and a slight decrease in peak pressure with increasing aspect ratio is exhibited. As the aspect ratio increases the relative amount of pure crushing making up the failure mode as a whole decreases, and radial and circumferential cracking and spalling activity increases. These failure mechanisms exert lower loads on the indentor face than crushing, and the overall effect is a reduction in total force on the indentor.

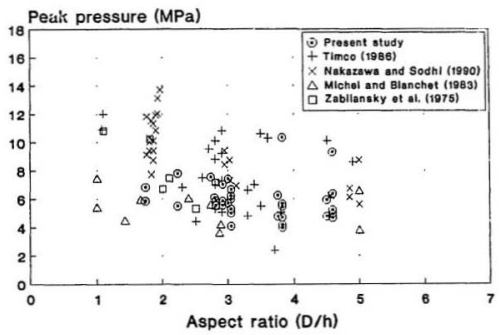

Figure 4.6: Peak pressure vs, aspect ratio $(D / h)$, including previous work (Nakazawa and Sodhi, 1990; Timco, 1986; Michel and Blanchet, 1983; Zabilansky et al., 1975). 


\subsubsection{Velocity effect}

Velocity is usually normalized with respect to the length of ice loaded during indentation to derive a test "strain rate". As described in Section 4.1.1, the traditional normalized velocity term of $V / 2 D$ is not a true strain rate, and should not be referred to as such. For the purposes of comparison with previously published results, $V / 2 D$ will be retained as a normalized velocity term but will be referred to as "indentation rate".

A plot of peak pressure vs. indentation rate including previously published results (Nakazawa and Sodhi, 1990; Timco, 1986; Michel and Blanchet, 1983; Zabilansky et al., 1975) is shown in Figure 4.7. The data agrees well with the previous results. For the present tests, indentation rate varied between $8 \times 10^{-4} \mathrm{~s}^{-1}$ and $2.3 \mathrm{~s}^{-1}$, and appeared to have some effect on peak pressure. Peak pressure appears to increase consistently, however slightly, with indentation rate up to $V / 2 D=0.2 s^{-1}$, after which a dip occurs. This dip coincides with the transition from intermittent crushing to continuous crushing, and is associated with a change in the behaviour of the structure from static to dynamic. This drop will be discussed in detail when indentor dynamics are addressed in Section 4.3.

\subsubsection{Contact area effect}

A "scale effect" of decreasing pressure with increasing contact area has been reported by Sanderson (1986). A plot of peak pressure vs. contact area including previously published work (Nakazawa and Sodhi, 1990; Timco, 1986; Michel and Bla.ıchet, 1983; Zabilansky et al., 1975) is shown in Figure 4.8. The present data agrees with previous work. Contact area varied only from $21 \mathrm{~cm}^{2}$ to $37 \mathrm{~cm}^{2}$, and no distinguishable decrease in peak pressure with increasing contact area is 


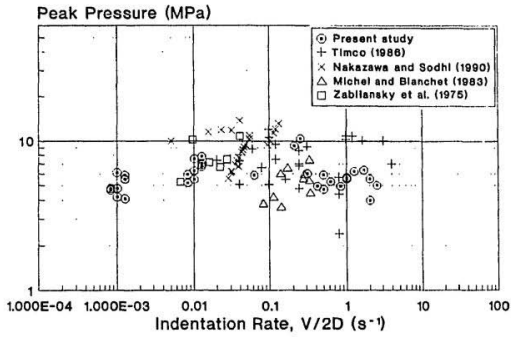

Figure 4.7: Peak pressure us. indentation rate (V/2D), including previous work (Nakazawa and Sodhi, 1990; Tinco, 1986; Michel and Blanchct, 198.; Zabilansky et al., 1975) 
evident. This result is not entirely unexpected, due to the small range of contact arcas used in the test series. The small range of contact area compared with previous work has produced a tight cluster of data points from the present study in Figure 4.8. For the sake of clarity, a plot of the present data alone is shown in Figure 4.9.

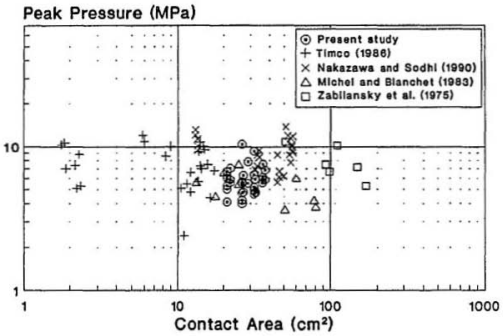

Figure 4.8: Peok pressure us. contact area, including previous work (Nakazawa and Sodhi, 1990; Timco, 1986; Michel and Blanchet, 1989; Zabilansky et al., 1975) 


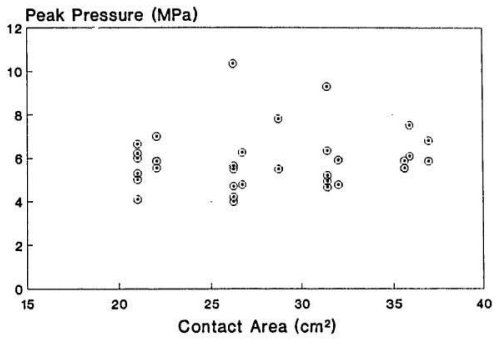

Figure 4.9: Peak pressure vs, contact area, present study alone 


\subsection{Dynamics}

\subsubsection{Characteristic failure frequency}

The characteristic crushing frequency was obtained through spectral analysis of $F_{x}$ and in some cases, $M_{y}$. This generally yielded a power spectrum with a dominant peak at the characteristic failure frequency (see Figure 4.10). When the resultant power spectrum yielded more than one peak with significant power, a visual check of the force-time record was used to verify the dominant failure frequency.

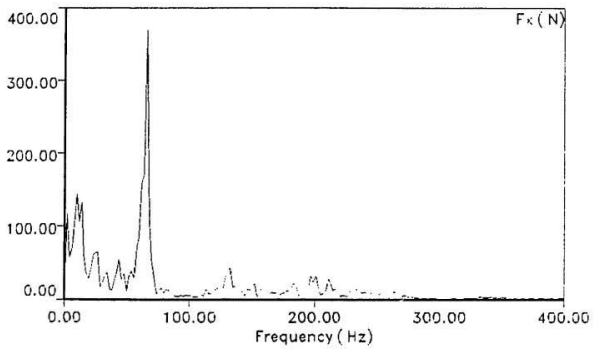

Figure 4.10: Typical power spectrum of $F_{x}$ time series

During test series Fresh1_HI, Fresh2.HI and Fresh3_HI, $F_{x}$ was sampled at $2000 \mathrm{~Hz}$ and passed through a $1 \mathrm{~Hz}$ (instead of $1 \mathrm{kHz}$ as in other tests) antialiasing filter. This unfortunate error rendered dynamic analysis of this signal useless for the noted tests. Comparison of $F_{x}$ with $M_{y}$ for other series where $F_{x}$ 
was properly filtered at $1 \mathrm{kHz}$ (Fresh4_HI, Fresh5_HI, Fresh6_HI, and Freshl_LO through Fresh6_LO) showed a nearly perfect match of the two signals under all conditions. A plot of $F_{x}$ and $M_{y}$ from a properly recorded test (Fresh6_LiL_Run2) illustrates this agreement (see Figure 4.11). Although the amplitude of peaks in the $M_{y}$ spectrum cannot be compared with the amplitude of peaks in the matching $F_{x}$ spectrum, the frequencies obtained from the $M_{y}$ spectrum are the same as those which would have been found from a properly filtered $F_{x}$ signal, as shown in Figure 4.12. Consequently, the $M_{y}$ time trace from test series Fresh1_HI, Fresh2_III and Fresh3_HI was used for spectral analysis to determine the characteristic crushing frequency for particular velocities.

Plots of the characteristic failure frequency normalized with respect to the natural frequency of the structure $\left(f / f_{n}\right)$ vs. aspect ratio $(D / h)$, and $f / \int_{n}$ vs. velocity $(V)$ are shown in Figure 4.13 and Figure 4.14, respectively. The natural frequency of the structure was found from plucking tests to be $63 \mathrm{~Hz}$. Variations in characteristic failure frequency occurred predominantly (and in a systernatic fashion) only with changes in velocity. Aspect ratio has no apparent effect on the crushing frequency, although the narrow range of aspect ratios used in this test series may not have been sufficient to allow any relationship to emerge.

The frequency of failure reaches a plateau at the natural frequency of the structure as velocity approaches $100 \mathrm{~mm} / \mathrm{s}$, and is "locked-in" at the natural frequency of the structure for higher test velocities. The increase in failure frequency up to this plateau is proportional to the normalized velocity, and once the plateau is reached it becomes independent of velocity. This is in agreement with the findings of Neill (1976), Sodhi and Morris (1986) and Singh ct al. (1990). Singh et al. also noted the "locking-in" of the dominant frequency at the natural frequency of the structure over a wide range of velocities. Similarly, velocity did 

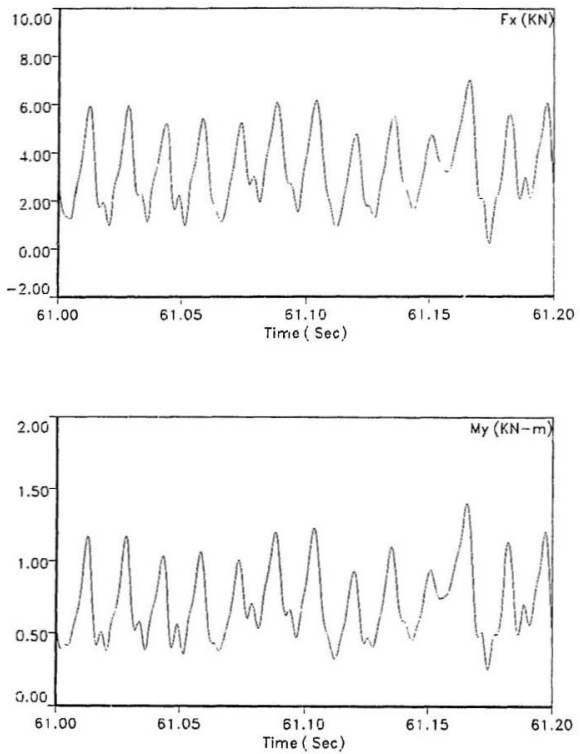

Figure 4.11: Portions of $F_{x}$ and $M_{y}$ from test Fresh6_HI_Run2 $(50 \mathrm{~mm} / \mathrm{s})$ 

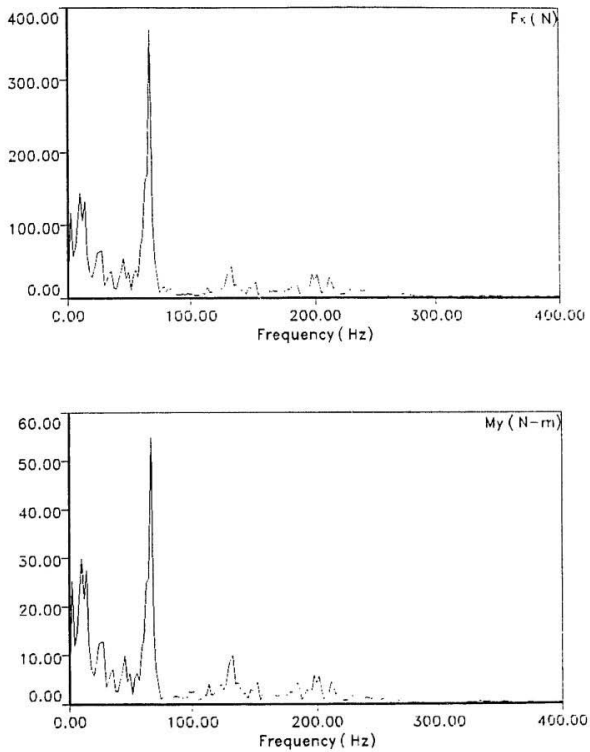

Figure 4.12: Power spectra of $F_{x}^{\prime}$ and $M_{y}$ from test Fresh6_HL_Run2 (50 mm/s) 


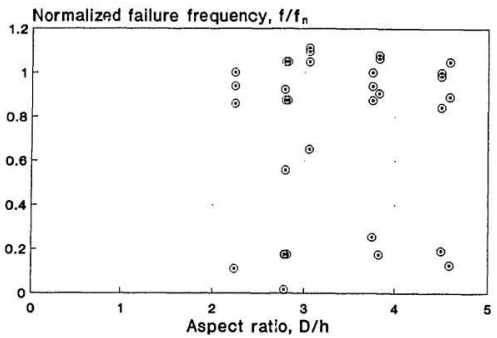

Figure 4.13: Normalized failure frequency vs. aspect ratio

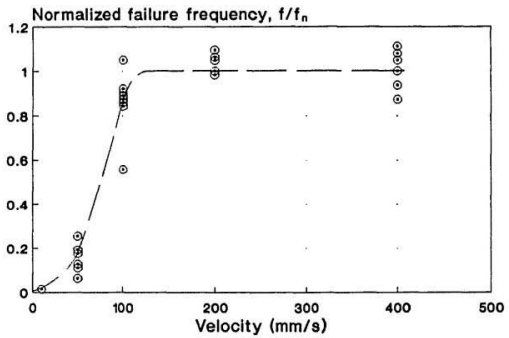

Figure 4.14: Normalized failure frequency vs. velocity 
not increase enough to push the dominant frequency above the natural frequency of the structure, but at 200 and $400 \mathrm{~mm} / \mathrm{s}$ higher frequencies did begin to appear in the spectrum.

Prior to lock-in, the indentor movements are characterized as transient or unsteady, and a sawtooth-shaped force-time trace was recorded. The indentor response decays significantly before the exciting force is again applied by the ice. At velocities above $100 \mathrm{~mm} / \mathrm{s}$ indentor oscillations become steady at the natural frequency of the structure. Figure 4.15 is a plot of indentor displacement at speeds of $50,100,200$ and $400 \mathrm{~mm} / \mathrm{s}$ for test Fresh6_H1_Run2 $(h=30 \mathrm{~mm}, D=100 \mathrm{~mm})$. When the exciting force (crushing) is applied at the same frcquency as the natural frequency of the structure a resonant condition should emerge where the structut al response is large and the load on the structure required to induce this response is small (Rao, 1986). It can be seen from Figure 4.15 that changes in the response amplitude with increasing velocity are small, although the mcan deflection of the indentor increases. At high indentation velocity $(\geq 100 \mathrm{~mm} / \mathrm{s})$ the intrusion of the crushed layer and the "intact" ice sheet prevents the full rebound of the indentor to the "equilibrium" position (displacement $u=0$ ). The mean position of the indentor is shifted in the positive- $x$ direction. This condition is similar to that described by Kärnä and Turenen (1990) as continuous crushing at high velocity. If velocity had increased above $400 \mathrm{~mm} / \mathrm{s}$, it is possible that oscillations of the indentor would decrease and a positive constant displacement induced by the mean ice force established, such that $u=F_{\text {mean }} / K$.

Jordaan et al. (1991) indicate that the structural stiffness $K$ has a significant effect on the crushing frequency and the amount of ice crushed per cycle. The static indentor stiffness was measured from the plucking tests as $K=9.4 \mathrm{MN} / \mathrm{m}$. The stiffness of the ice, $K_{l}$, can be calculated as 

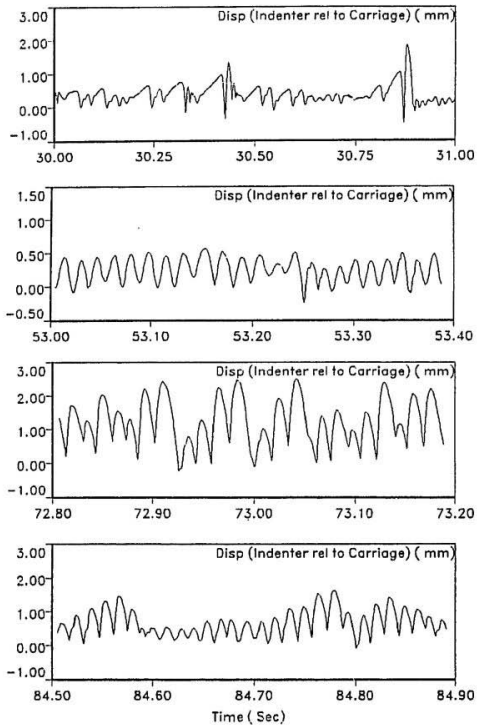

Figure 4.15: Indentor response at velocities of $50 \mathrm{~mm} / \mathrm{s}, 100 \mathrm{~mm} / \mathrm{s}, 200 \mathrm{~mm} / \mathrm{s}$ and $100 \mathrm{~mm} / \mathrm{s}$ 


$$
K_{I}=0.085 \pi E h
$$

where the ice is assumed to be a semi-infinite elastic plate and the total load is distributed uniformly over the indentor width (Jordaan and Timco, 1988). For a narrow indentor, a uniform load distribution is a reasonable assumption. Using the values of $h$ from Table 3.3 and $E=10000 \mathrm{MPa}$ for rapid loading (Jordian and Timco, 1988), the stiffness of the ice sheet can be calculated as varying from $70 \mathrm{MN} / \mathrm{m}$ to $124 \mathrm{MN} / \mathrm{m}$, and the ratio of ice stiffness to indentor stiffuess $\left(K_{I} / K^{\prime}\right)$ ranges from 7.5 to 13 . These ratios are considerably higher than the ice to structure stiffness ratio of 4 obtained by Timco (1986), as reported by Jordaan and Timco (1988). Although the absolute stiffuess of the present structure is greater than that of Timco's structure, the present structure is at least twice as compliant as that of relative to the ice tested (Timco, 1986).

The amount of ice crushed per cycle and the high-velocity frequency dependence, however, lead to the conclusion that the indentor behaved as a relatively stiff structure when dynamic behaviour was excited. The higher the compliance of a structure, the lower the =esulting crushing frequency will be for a given velocity and ice thickness. A more flexible structure will deflect more under a given load and crushing events will occur less frequently. The flexible structure will also release more strain energy and subsequently crush more ice per cycle. The region of velocity dependence in Figure 4.14 between $50 \mathrm{~mm} / \mathrm{s}$ and $100 \mathrm{~mm} / \mathrm{s}$ can be approximated by a line of slope $f / f_{n} V=0.013$. Multiplying this value by the natural frequency of the structure, $f_{n}$, and the thickness of the ice, $h$, gives a dimensionless number $F=f h / V=19$. Typically in laboratory scale tests $F$ ranges from 3-5, while for medium scale tests conducted at Pond Inlet, $F$ was as high as 500 , and for the large-scale MOLIKPAQ events ranged from 20-100 
(Jordaan et al., 1991). As the stiffness of the structure increases, $F$ should increase. The structure for the present test series is relatively stiff by this standard, compared to typical laboratory scale tests. This apparent contradiction is due to the different structure stiffnesses under static and dynamic loading. The region between $0 \mathrm{~mm} / \mathrm{s}$ and $50 \mathrm{~mm} / \mathrm{s}$ in Figure 4.14, when indentor behaviour was essentially static, can be approximated by a line having a slope $f / f_{n} V$ somewhere between 0.0013 and 0.0024 . Again multiplying by $f_{n}$ anc $h, F$ is found to range between 2.5 and 4.5. For purposes of comparison, Timco (1986) obtained a value

of $F=3$ (Jordaan and Timco, 1988). When the present structure is statically loaded (at low velocities) it behaves as a relatively flexible structure similar to ot her laboratory indentor structures. As a constant dynamic response is excited, however, the higher dynamic stiffness produces higher crushing frequencies and shorter damage lengths.

\subsubsection{Damage length}

When a rigid indentor crushes ice at a frequency $f$, then each crushing cycle takes $1 / f$ seconds and the indentor moves a distance of $V / f \mathrm{~mm}$ each cycle. This distance $V / f$ is called the damage zone or damage length, $l$, as discussed in Section 2.2. A portion of the actual length of ice crushed in a single cycle may be sintered together at the end of the extrusion cycle to form a reconstituted mass between the indentor and the original "ihiact" ice. The presence of the sintered ice mass prevents travel of the indentor through the full damage length, effectively reducing the damage length as determined from the frequency respense of the structure. It follows that the crushing length predicted by $V / f$ is an underestimate of the actual crushing length. Unfortunately, it is extremely difficult to experimentally 
determine the actual crushing length per cycle.

The ratio of damage length to ice thickness, $V / f h$, is typically betwecn 0.2 and 0.5 (see Section 2.2). Plots of $V / f h$ vs. aspect ratio $(D / h)$, and $V / f h$ vs. velocity $\left(V^{\prime}\right)$ are shown in Figure 4.16 and Figure 4.17 respectively. The damage length ranged between $0.06 h$ and $0.4 \delta h$, i.e. between $6 \%$ and $18 \%$ of the ice thickness was crushed in each cycle. Most values, however, were below about $0.25 \mathrm{~h}$. Aspect ratio has no discernible effect on $V / f h$, while velocity has a definite effert.

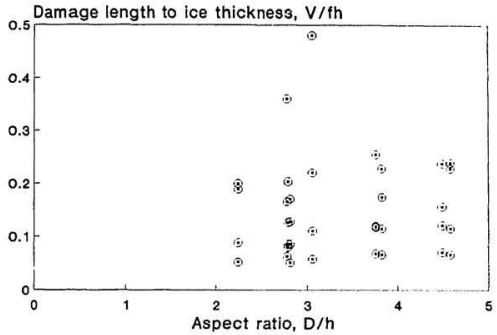

Figure 4.16: Damage length to ice thickness ratio vs. aspert ratio

For velocities below $50 \mathrm{~mm} / \mathrm{s}$, the damage length was usually between $0.1 \mathrm{~h}$ and $0.2 h$. Damage lengths up to about $50 \%$ of the ice thickness were calculated. These values are in agreement with the lower range of values suggested by proviously published results. As discussed in Section 4.3.1, the compliance of the structure has a significant effect on its dynamic response. Typical values of $f h / V$ for laboratory scale indentation tests range from 3-5, while values of $f h / V$ for the 


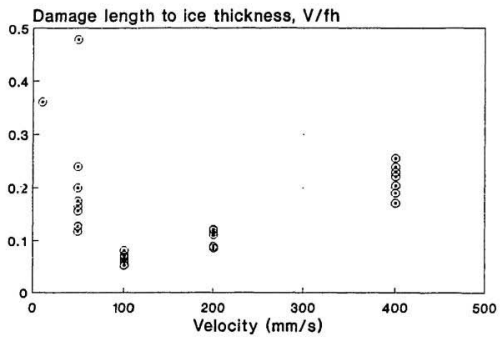

Figure 4.17: Damage length to ice thickness ratio vs. velocity

present tests are near 20, indicating high stiffness. Consequently, lower damage lengths are produced. At the point where locking-in of the characteristic failure frequency occurs $(V \approx 100 \mathrm{~mm} / \mathrm{s})$, the value of $V / \int h$ drops tw 0.06 and then begins increasing linearly with velocity. As $f$ is locked near the natural frequency of the structure, the value of $V / f h$ becomes directly dependent on $V$, increasing accordingly.

\subsubsection{Higher frequency observations}

Figure 4.18 is a plot of the $F_{x}$ trace and the indentor displacement-time trace from a $200 \mathrm{~mm} / \mathrm{s}$ test (Fresh6.HI_Run2). The force trace exhibits a steady-state double beat pattern with two distinct peaks in every full cycle. The largest peak generally occurs at the maximum indentor displacement and coincides with a crushing event, while the smaller peak occurs as the indentor rebounds and may 
be associated with a second crushing event or some extrusion process. This implies that there are two out-of-phase failure processes occurring at a frequency near the natural frequency of the structure. Occasionally, however, a smaller peak can be observed on the "up-swing" of the larger force peak. A more likely explanation of the double beat force-time trace is the superposition of two frequency components in the force: one at the natural frequency of the structure and another at its higher frequency of vibration. The power spectrum of this time series is shown in Figure 4.19 and confirms the presence of two distinct frequencies at approximately $65 \mathrm{~Hz}$ and $200 \mathrm{~Hz}$. A frequency component near $200 \mathrm{~Hz}$ was observed in several other tests. If this component was evidence of ice failure at some frequency above: the natural frequency of the structure, it would have some variability. The const ancy of the higher frequency at $\approx 200 \mathrm{~Hz}$ indicates that it is the result of excitation of some different mode of structural vibration. A complete dynamic analysis of the indentor-carriage system must be performed to confirm the existence of this higher frequency in the structure, to ensure that it is not related to some ice failure phenomenon such as the extrusion process.

\subsection{Sieve analysis}

A portion of the crushed ice mass extruded from the indentor-ice interface was collected and passed through a series of 4 sieves to determine the size distribution of the crushed particles. The ranges of particle sizes, as determined hy sieve sizes, were $>4.76 \mathrm{~mm}, 4.76-2.38 \mathrm{~mm}, 2.38-1.19 \mathrm{~mm}, 1.19-0.85 \mathrm{~mm}$, and $<0.85 \mathrm{~mm}$. The top sieve usually contained a number of larger ice pieces spalled from the parent sheet during indentation. The typical spall was roughly oval-shaped, with a thickness of less than $5 \mathrm{~mm}$ and dimensions of approximately $20 \times 30 \mathrm{~mm}$. 


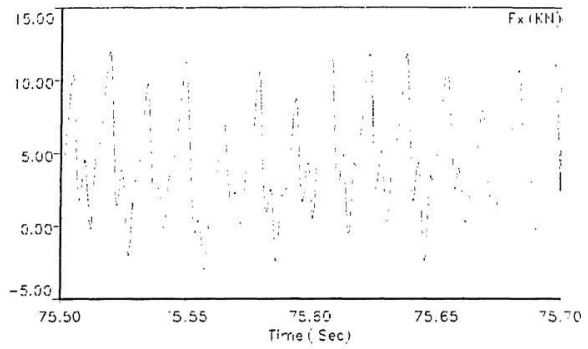

Figure 1.18: Portion of $F_{x}$ time series with double bent pattern

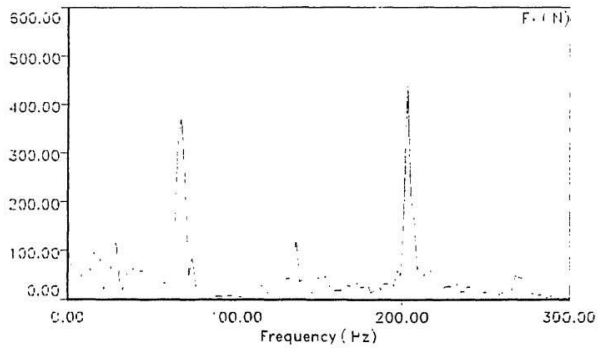

Figure 4.19: Power spectrum of double beat time series, showing two distinct frequencies 
A plot of the percentage of crushed ice passed through cach sieve for different velocities is shown in Figure 4.20.

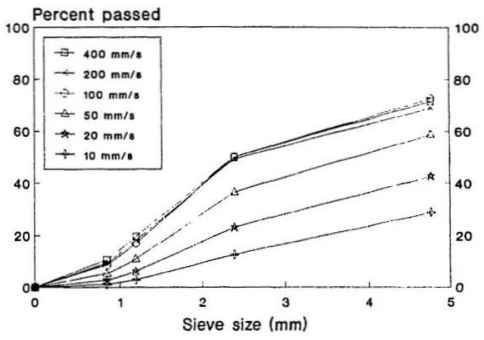

Figure 4.20: Sieve analysis results: percentage passed vs. siebe size

The increase in percent passed with increasing velocity indicates that the fineness of the crushed ice particles increases with velocity. After the ice is initially crushed, further grinding and crushing take place within the crushed layer as the particles are extruded from the ice-structure interface. The increase in particle: fineness with velocity may be attributed to an increase in the anount of further crushing within the layer at higher velocities.

It is worth noting that some of the particles ejected from the ice-structure: interface are actually several particles joined logether by either re-freezing or some sintering process, and the particle sizes determined by the sieve analysis are almost certainly larger than the actual initial sizes of the crushed grains. The sliding of 
particles within the crushed layer will induce friction melting on the surface of the particles. Iligh local pressures can exist within the crushed layer as well, inducing pressure-melting and possibly sintering of particles. If inter-granular motion stops while several wetted particles are in contact, they can re-freeze to form a larger single particle. Examination of individual crushed particles was not performed for the present tests. Examination of particles from the 1990 Hobson's Choice Ice Island tests definitely revealed that some of the ejected crushed particles are re-frozen or sintered groups of smaller particles (Kenny et $a^{\prime} ., 1991$ ). 


\section{Chapter 5}

\section{RESULTS AND ANALYSIS:}

\section{INCLINED INDENTORS}

\subsection{Failure modes}

Visual records in the form of still photographs and videotapes were used in conjunction with first-hand observations to examine the failure mode of the ice during each test. Of particular interest was the transition from crushing failure to Hexural failure as ice thickness $h$, indentor angle $\alpha$ and test speed $V$ varicd. Tests were performed at velocities from $10 \mathrm{~mm} / \mathrm{s}$ to $400 \mathrm{~mm} / \mathrm{s}$ and indentor angles of $5^{\circ}, 10^{\circ}$, $20^{\circ}$ and $30^{\circ}$ from a vertical plane. Nominal ice thicknesses were $30 \mathrm{~mm}, 40 \mathrm{~mm}$ and $50 \mathrm{~mm}$. Plcts of all data from tests Fresh5_IIl_Run2 and Fresh5_L_O_Run2 $\left(D=120 \mathrm{~mm}, h=40 \mathrm{~mm}, \alpha=20^{\circ}, V=10,20,50.100,200\right.$ and $\left.400 \mathrm{~mm} / \mathrm{s}\right)$ are presented in Appendix B.

Three primary failure modes were observed: continuous crushing; mixed crush- 
ing and flexure; and pure flexural tamure. Continuous crushing occurs when no flexural failure events are observed during a test. This failure mode may also contain shear failure adjacent to the indentor face. If the crushing is interrupted by sporadic flexural events, the failure was described as "mixed mode". If flexural failure is regular the failure mode is said to be pure flexure, even though short periods of crushing may occur before each event. Examples of the force-time series for each of these failure modes are shown in Figure 5.1.

For the $5^{\circ}$ and $10^{\circ}$ indentors continuous crushing dominated. Radial and circumferential cracking patterns similar to those for the vertical indentors were observed. Usually, two radial cracks formed from the corners of the indentor at the onset of indentation, and occasionally a third radial crack formed from the center of the indentor face. At speeds between 10 and $50 \mathrm{~mm} / \mathrm{s}$, these cracks could extend up to $5 \mathrm{~m}$ into the intact ice sheet. As the velocity increased, the length of the radial cracks shortened and tended to form only at the indentor corners. For $400 \mathrm{~mm} / \mathrm{s}$ tests, a cracking pattern often observed was regular, short radial cracks shooting into the ice at $45^{\circ}$ from the indentor corners. These cracks were about $0.5 \mathrm{~m}$ long and were separated by approximately $10 \mathrm{~cm}$ spacings along the broken track. Circumferential cracks sometimes formed at a radius of about $1 \mathrm{~m}$ from the indentor face. Despite the formation of circumferential cracks, the indentor usually continued crushing the ice without rotating and clearing the broken ice piece as expected for an inclined indentor. The likelihood of circumferential cracking, and the radius of any cracks, decreased as velocity increased.

For the $20^{\circ}$ and $30^{\circ}$ indentors, indentor velocity and ice thickness had the greatest effect on failure mode. At test speeds of 20 and $10 \mathrm{~mm} / \mathrm{s}$, the ice failed predominantly in flexure, with short periods of crushing sometimes occurring prior to a flexural event. At higher speeds (50 to $400 \mathrm{~mm} / \mathrm{s}$ ) the failure mode was 

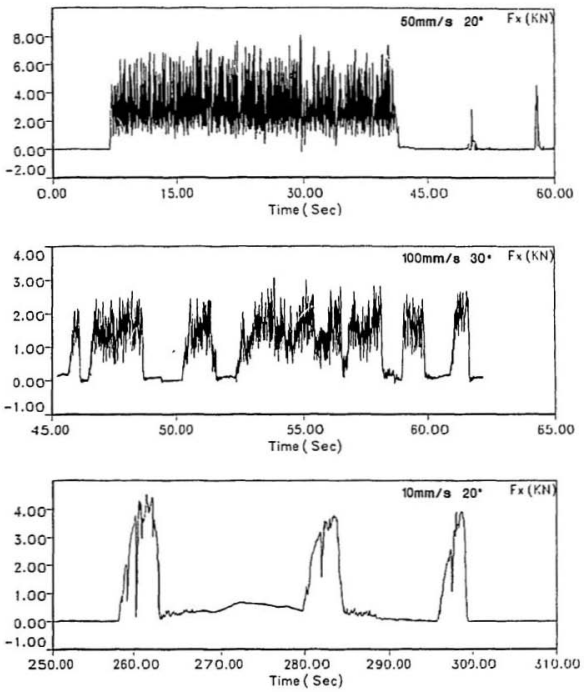

Figure 5.1: Typical force-time histories from inclinet indentalion tests: a) continuous crushing; b) mixeu trushing and flexure; c) pure flexure 
influenced by ice thickness, with flexural failure events occurring less often in thicker ice. The flexural failure events were characterized by the formation of multiple circumferential cracks, usually two at a time, and sometimes even three at a time. When flexural failure dominated, radial cracks sometimes formed after circumferential cracking. The first circumferential crack usually formed at a radius between $0.75 \mathrm{~m}$ and $1.5 \mathrm{~m}$ from the indentor face. A fraction of a second later, a second "subsidiary" circumferential crack almost always formed about 0.1 to $0.3 \mathrm{~m}$ from the indentor face. The subsidiary circumferential crack (closer to the indentor) would form a discrete ice slab which would rotate and clear. The length of the broken ice piece was the distance of the second crack from the indentor, while the width was sometimes over $1 \mathrm{~m}$. If the piece was large, it was often rotated and "sandwiched" between the advancing indentor and the level ice edge and broken into smaller pieces. When the indentor next contacted the ice edge, flexural failure would occur at the next (previously-induced) circumferential crack, and the load required to induce this failure was correspondingly lower. Typically, a large peak force where two or three circumferential cracks were formed would be followed by one or two peaks between $25 \%$ to $75 \%$ of the first peak, as described above. Each peak is separated by a stretch of low or zero load as the indentor travcrses open water or clears broken pieces. Figure 5.2 is a portion of the $F_{x}$ time series for $V=20 \mathrm{~mm} / \mathrm{s}$ from Fresh5.LO_Run2 featuring the formation of a principal circumferential crack and two subsidiary cracks. A series of sketches illustrating the failure sequence for this portion of the time series is presented in Figure 5.3.

The formation of the subsidiary cracks is due to three possible mechanisms: the formation of a truncated wedge after initial circumferential cracking, buckling failure or shear cracking. These explanations are discussed below. Unfortunately, 


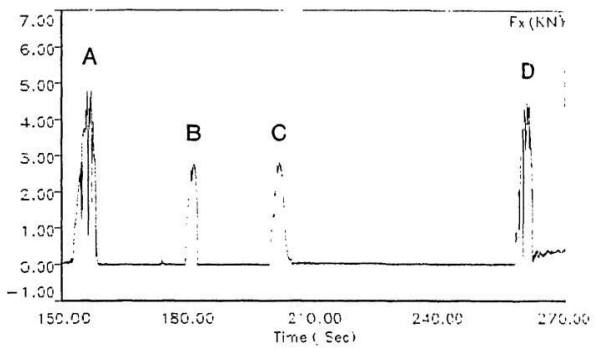

Figure 5.2: Portion of $F_{s}$ series from test Fresh5_LO_Run2 featuring formulion of principal and "subsidiary" circumferential cracks

A

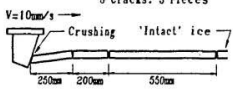

C

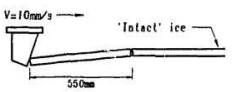

B

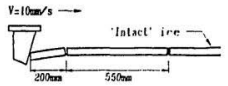

D

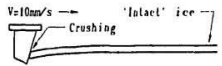

Figure 5.3: Illustration of failure sequence for time series of Figure 5.2 
much previous work with inclined structures has concentrated on conical structures, and it will have to hr assumed that the failure mechanisms described can be extended to planar surfaces.

The first circumferential crack was not always observed to propagate to the free ice edge. Assuming that just after the first circumferential crack is created two radial cracks emanate from the indentor corners, a truncated wedge is formed. According to Nevel (1972):

$$
\frac{6 P_{w}}{b_{o} \sigma h^{2}}=1.10+2.40\left(a / L_{c}\right)-0.10\left(a / L_{c}\right)^{3}
$$

and

$$
x / L_{c}=1.83+0.916 v+0.292\left(a / L_{c}\right)^{2}
$$

where

$$
L_{c}=\left[\frac{E h^{3}}{12 \rho_{w} g}\right]^{1 / 4}
$$

$P_{v}=$ ultimate vertical load

$b_{o}=$ a constant, such that $b=b_{o} x$

$b=$ width of the wedge at a distance $x$ from the wedge tip

$x=$ position of maximum stress, i.e. distance at which failure occurs

$a=$ loading length at wedge tip

$\nu \quad=$ Poisson's ratio

$\rho_{w}=$ density of water

$g=$ gravitational acceleration

$E=$ elastic modulus of ice 
For the first peak shown in Figure 5.2, $\sigma_{j}=927 k P_{a}, b_{o}=2 \mathrm{~m}, h=35.6 \mathrm{~mm}$, $L_{\mathrm{c}}=119 \mathrm{~cm}$ and $a=0.10$. An ultimate vertical load of $P_{w}=530 \mathrm{~N}$ is predicted using equation (5.1). From the vertical force-time record for this peak, $P_{\mathrm{z}}$ was measured at $680 \mathrm{~N}$. Nevel's equation (5.2) enables prediction of the distance of cracking. For this case $\left(a / L_{c}=0.10\right)$ and the crack distance is predicted to be about $0.5 \mathrm{~m}$. This agrees well with the distance of $0.45 \mathrm{~m}$ associated with the first subsidiary crack in Figure 5.2. The creation of the second subsidiary crack is not explained, however, and the radial cracks (essential for this failure mechanism) were not always observed in cases where the subsidiary cracks formed.

If the indentor angle $\alpha$ is small, and the friction between the ice and inclentor surface high, it is conceivable that , high horizontal load could result in buckling failure. The formation of two or three cracks virtually simultancously is also consistent with buckling failure. After the initial circumferential crack is formed, hinged boundary conditions are created at both the ice-indentor interface (due to the roughness of the indentor surface) and the first crack. A subsidiary crack: may form at the halfway distance, a prediction in agreement with observations of the present tests. Buckling is associated with low indentation rates, wide structures and thin ice, however, none of which characterize the present tests. Timco (1986) predicts that buckling will occur at indentation rates below $0.03 \mathrm{~s}^{-1}(V \approx 7 \mathrm{~mm} / \mathrm{s}$ for the present test geometry) for low aspect ratios. In a recent survey of all buckling failures observed in laboratory scale indentation tests, Blanchet et al. (1989) also note that at aspect ratios below 5 and indentation velocities above $10 \mathrm{~mm} / \mathrm{s}$, no buckling occurred. The formation of one or two subs:diary cracks occurred at velocities up $10400 \mathrm{~mm} / \mathrm{s}$ in the present tests.

Wessels and Kato (1988) describe an interesting dependence of the size of the broken ice pieces on the ice-structure friction angle and the thickness of the 
ice. For the case of pure bending fallure, elastic plate theory predicts the length of broken ice piece to be of the order of magnitude of the characteristir length. It follows that as the characteristic length of the ice increases with increasing thickness, the size of the broken ice piece will increase as well. This correlation has been observed to hold true in experiments with smooth structures, where the indentation forces result in pure flexural failure. For rough structures, however, the size of the broken ice pieces is observed to decrease with increasing thickness. This is due to a transition from pure flexural failure to combined flexure and shear failure. The higher coefficient of friction of the rougher surface means a greater normal load must be applied to produce the same deflection of the ice shcet. Larger horizontal forces are developed at the interface, and the presence of an out-of-plane deflection leads to shear failure at some distance from the indentor rather than only pure crushing at the interface. Wessels and Kato further note that more than one circumferential crack forms at high velocities for combined flexure and shear. In the case of the present tests the rough surface of the indentor, small indentor inclination, and relatively thick ice make the presence of shear forces highly likely. The subsidiary cracks are probably formed, by a combination of both the shear mechani sm and dynamic buckling.

At higher speeds ( 50 to $400 \mathrm{~mm} / \mathrm{s}$ ) the failure mode was influenced by ice thickness, with flexural failure pvents occurring less often as ice thickness increased. Figure 5.4 shows the dominant mode of failure of each test plotted against indentor angle and velocity normalized with respect to ice thickness. This "map" is divided into three areas: flexural failure, crushing failure, and a mixed region where both modes occurred, sometimes in the same test. Although gaps in the data exist, the map gives a rough indication of the conditions under which a particular mode of failure is likely to occur. 


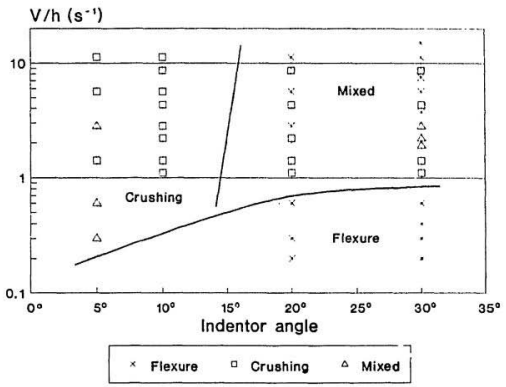

Figure 5.4: Failure mode map for tests with inclined indentors 
As velocity incieases, it is expected that the inertial resistance of the water to the downward acceleration of the ice sheet will increase, and the failure mode may change from flexure to crushing (Sodhi, 1987). Overall, this was found to be true for this test series, as the total number of flexural failure events decreased with increasing velocity. It was often observed, however, that crushing occurred primarily at the start of a run, i.e. at the first velocity $(50$ or $20 \mathrm{~mm} / \mathrm{s})$ to be tested, and changed to flexure some time into the run. Once one flexural failure was induced, the rest of the run was likely to be dominated by flexural failure. The change to flexure sometimes occurred while the indentor was still moving at the first velocity. The relatively undamaged state of the ice sheet at the start of a test run may allow crushing to continue for a short period of time, until the number of radial and circumferential cracks in the ice reaches a level where flexural failure inevitably occurs. The probability of encountering some flaw in the ice sheet leading to flexural failure also increases with the distance moved through the ice.

\subsection{Peak horizontal forces}

The peak horizontal force $\left(F_{x_{\text {peak }}}\right)$ on the indentor face was found using the DAS_CALC software at the IMD. This peak force was normalized with respect to the square of the ice thickness $h$, and the flexural strength of the ice $\sigma_{f}$, to give the "normalized peak horizontal force", $H$, such that:

$$
H=\frac{F_{x_{\text {peak }}}}{\sigma_{f} h^{2}}
$$

All inclined indentors had a width of $120 \mathrm{~mm}$, and the $120 \mathrm{~mm}$ vertical indentor 
is included in this analysis for purposes of comparison as a $0^{\circ}$ "inclined" indentor.

\subsubsection{Indentor angle effect}

A plot of $H$ as a function of indentor angle is shown in Figure 5.5. The peak forces on the indentor increase as $\alpha$ approaches $0^{\circ}$.

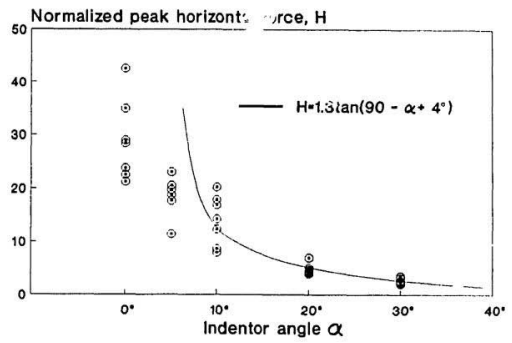

Figure 5.5: Normalized peak horizontal force vs. indentor angle

Previously published studies for inclined indentors have excluded crushingdominated peak forces (Michel and Picard, 1989; Haynes $e l$ al., 1983)) from analysis, and obtained a function of the form $H=a \tan (\alpha+\phi)$, where $\alpha$ is the indentor angle, $\phi$ the friction angle and $a$ some constant. The solid line in Figure 5.5 represents a best-fit curve of $H$ for indentor angles of $10^{\circ}$ and greater (i.e. the curve was not fit to data points' at $5^{\circ}$ or $\left.0^{\circ}\right)$ : 


$$
H=1.3 \tan \left(90-a+4^{\circ}\right)
$$

This function greatly overpredicts $H$ for indentor angles close to vertical, where crushing becomes predominant. Equation (5.4) assumes that the ice will fail in flexure, and the resulting peak stress predicted for indentor angles below $10^{\circ}$ is much higher than the crushing strength of the ice. The application of equation (5.4) is not valid for conditions where crushing behaviour predominates.

\subsubsection{Velocity effect}

A plot of the normalized peak horizontal force, $H$, vs. indentor velocity is shown in Figure 5.6, with each indentor angle plotted as a separate series. The force initially increases to some peak value, then drops at $V / h \approx 2$ and begins incrcasing once again, although at a slower rate, as velocity increases. This effect becomes less dramatic as the indentor angle increases, and $H$ is almost velocity-independent for the $30^{\circ}$ indentor.

The explanation for this behaviour is related to the dynamic response of the structure. For the $0^{\circ}, 5^{\circ}$ and $10^{\circ}$ indentors, crushing was the dominant failure mode and the structural rusponse was similar to that for vertical indentors. Once the structural response becomes locked-in at the natural frequency $(63 \mathrm{~Hz})$ at $V / h$ near 2 , the load decreases to a minimum and again begins increasing with increasing velocity, as detailed in Section 4.3. At indentor angles of $20^{\circ}$ and $30^{\circ}$ the failure mode is predominantly bending, and the natural frequency of the structure is not excited. Consequently, the initial rise and fall of $H$ noted for lower angle indentors is less dramatic or non-existent. 


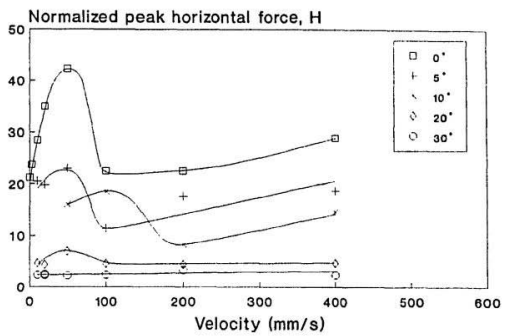

Figure 5.6: Normalized peak horizontal force vs. indentor wclocity

\subsection{Dynamics}

From observations of the tests, the first circumferential crack was seen to usually occur at a distance close to the characteristic length of the ice sheet, between I and $1.5 \mathrm{~m}$ from the indentor face. This agrecs well with breaking lengths observed by Frederking and Timco (1985) and Michel and Picard (1989). As discussed in Section 5.1, a second, subsidiary crack usually formed at some point roughly botween the initial circumferential crack and the indentor, and sometimes at thirl subsidiary crack formed even closer to the indentor face. These picces would rotate and clear, and the indentor would traverse the resulting open water before again contacting the ice edge. The piece sizes used in the following analysis are determined by the shortest cracking distance when more than onc circumferential crack was formed. This distance also corresponded to the distance travelled 
between flexural failure peaks.

The "single icebreaking frequency" was determined for tests where bending was the dominant mode of failure by performing spectral analysis of the resulting force-time series. These frequencies were double-checked by visually examining the individual time series. For test series Fresh3_HI_Run3, the $F_{x}$ signal was inadvertantly filtered at $1 \mathrm{~Hz}$ (instead of at $1 \mathrm{kHz}$ as for other tests) and rendered useless for spectral analysis. As detailed in Section 4.3, the properly recorded $M_{y}$ signal was used for this test to determine the frequency content of the horizontal force on the indentor. A total of 18 data points were obtained where bending failure dominated (four from test Fresh3_HI_Run3). Figure 5.7 is a plot of the single icebreaking frequency vs. velocity. A trend of increasing frequency with velocity is evident.

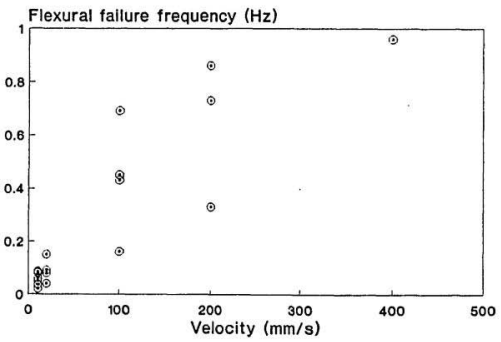

Figure 5.7: Single icebreaking frequency us. velocity

From the ingle icebreaking frequency the, average broken ice piece length 


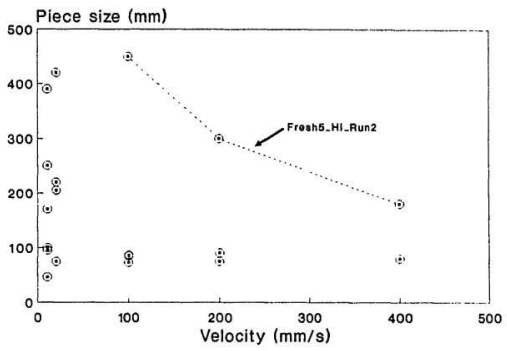

Figure 5.8: Broken ice piece size vs. velocily

can be determined. The period $(1 / f)$ times the test velocity gives the dist.ance travelled between flexural events, which is presumed close to the broken ice piece size. Even when flexure was the dominant failute mode, however, it portion of the intact sheet was usually crushed before bending failure occurred for many tests. A better method of determining broken ice piece size, then, is to measure the time between flexural failure and new contact between the indentor and ice sheet (i.e. the time where the force on the indentor is at zcro or some very low d due) and multiply this value by the test velocity. This method of calculating broken piece size gave values ranging from $100 \mathrm{~mm}$ to almost $500 \mathrm{~mm}$, which agrce well with observed broken ice piece sizes. A plot of broken ice piece size vs. velocity is presented in Figure 5.8. The dynamic effect of decreasine broken piece size with increasing velocity as observed by Valanto (1989) is not clearly demonstrated here, probably due to the limited number of data points. For test Fresh5_HI_Run2, 
however, a definite decrease in piece size is observed with increasing velocity, as indicated by the dashed line in Figure 5.8. The maximum picce size decreases from $450 \mathrm{~mm}$ at $100 \mathrm{~mm} / \mathrm{s}$ to about $200 \mathrm{~mm}$ at $400 \mathrm{~mm} / \mathrm{s}$. The smallest piece sizcs, however, were also obscrved at the lowest test velocities.

The characteristic length of the ice sheets ranged from $0.90 \mathrm{~m}$ to $1.26 \mathrm{~m}$ (see Table 3.3). A plot of the ratio of piece size to characteristic length vs. velocity is shown in Figure 5.9. Most failure occurred at between $10 \%$ and $40 \%$ of the characteristic length. These values are lower than those reported by Frederking and Timco (1985) and Michel and Picard (1989), due to the formation of one or more subsidiary circumferential cracks during failure.

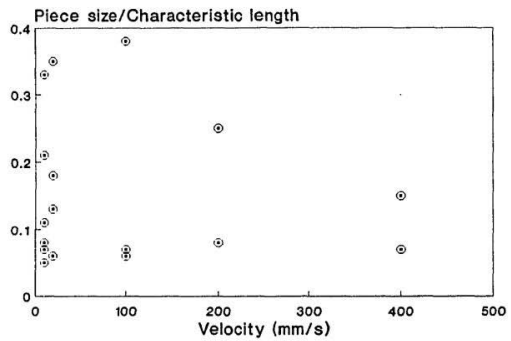

Figure 5.9: Ratio of broken ice piece size to characteristic length vs. velocity 


\section{Chapter 6}

\section{CONCLUSIONS}

The vertical indentation experiments produced several results similar to those observed by several previous researchers. The indentors used were relatively narrow (aspect ratio ranged from 1.7 to 4.6 ), and brittle crushing was the dominant failure mode. Radial cracking, spalling and occasional circumferential cracking were also observed. These failure modes occurred at combinations of velocity and aspect ratio which closely followed the "failure mode map" developed by "Timco (1986) for flat vertical indentors. The maximum force on the structure was 29.1 $k N$ and peak pressures (averaged over the indentor area) ranged from 4 to 11 $M P a$, in good agreement with previous work. Comparisous of peak pressure bitween different experiments must consider the duration of individual test runs, however, as a longer test run will usually produce a higher peak pressure. The variation of peak pressures as velocity, ice thickness and inclentor width changed confirmed behaviour observed by previous researchers. As aspect ratio increased the peak pressure on the structure slightly decreased. The failure mode at higher aspect ratios consisted of a lower proportion of pure crushing failure and increas- 
ing proportions of spalling and radial and circumferential cracking. Indentation rate had an effect on peak pressure as well. Peak pressure increased slightly with velocity until a steady vibration was induced in the structure somewhere between test velocities of $50 \mathrm{~mm} / \mathrm{s}$ and $100 \mathrm{~mm} / \mathrm{s}$. Once this dynamic response emerged, the load exerted on the structure dropped.

This transition from a static loading condition to a dynamic loading condition occurred, as stated above, between the velocities of $50 \mathrm{~mm} / \mathrm{s}$ and $100 \mathrm{~mm} / \mathrm{s}$. At velocities below $50 \mathrm{~mm} / \mathrm{s}$, ice was crushed intermittently, producing a sawtsothshaped force-time trace. The ice crushing frequency in this range linearly followed test velocity, and the dimensionless number $F=f h / V$ had a value between 2.5 and 4.5 (see Figure 4.14, Section 4.3). Typically, for relatively compliant laboratory-scale structures $F$ ranges from 3-5, while for stiffer structures $F$ can reach as high as 500 . The measured stiffness, $K$, of the structure was high, but the high in-plane stiffness of the thick freshwater ice produced a relatively compliant ice-structure system. The effort to produce a very stiff structure was somewhat undermined by the high strength and stiffness of the tested ice sheets.

At velocities above $50 \mathrm{~mm} / \mathrm{s}$ a dynamic loading condition emerged: a harmonic force-time trace was observed and the response frequency of the structure became locked at approximately $63 \mathrm{~Hz}$, the natural frequency of the structure. The response frequency remained locked at $63 \mathrm{~Hz}$ even as velocity was increased to $400 \mathrm{~mm} / \mathrm{s}$. This behaviour has been reported by several researchers in the literature, including Singh et al. (1990). For the region between $50 \mathrm{~mm} / \mathrm{s}$ and $100 \mathrm{~mm} / \mathrm{s}$ in Figure 4.14, the value of $F=f h / V$ was found to be approximately 20. The peak pressures exerted on the structure dropped when this dynamic condition emerged, and indentor deflection also decreased. Essentially, the indentor behaved as a stiffer structure than in the static loading condition. The 
damage length $l$, or length of ice crushed with each cycle, ranged from $0.06 \mathrm{~h}$ to $0.5 \mathrm{~h}$. These values are again low compas 2 do typical laboratory results. Due to the relative stiffness the structure in the dynamic condition, less deflection of the indentor occurs before the crushing strength of the ice is exceeted, and less elastic strain energy is returned to the ice. At very high $x$ iocities, $200 \mathrm{~mm} / \mathrm{s}$ and $400 \mathrm{~mm} / \mathrm{s}$, a second frequency near $200 \mathrm{~Hz}$ began to appear in the prower spectrum of the structure's response. This higher frequency was probably due to the excitation of some different mode of structural vibration rather than ice crushing at a higher frequency or some extrusion phenomenon. A complete dynamic analysis of the indentor-carriage system must be performed to confirm the existence of this higher frequency in the structure. The transition from "static" behaviour to "dynamic" behaviour could have been better studied if more test velocities between $50 \mathrm{~mm} / \mathrm{s}$ and $100 \mathrm{~mm} / \mathrm{s}$ had been included in the trst series. At $50 \mathrm{~mm} / \mathrm{s}$ the indentor behaved as a relatively compliant, static structure whils at $100 \mathrm{~mm} / \mathrm{s}$ the "locked-in" condition had been reached.

The inclined indentation tests produced mixed ice failure modes of crushing and flexure. The failure mode was influenced by indentor angle, ice thickness and indentor velocity. Indentor angle affects the proportion of total load applied in the in-plane and transverse directions. If the in-plane load exceeds the compressive strength of the ice before the transverse load produces sufficient deflection and bending stresses to induce a bending failure, the failure mode will be clominated by crushing. Flexural strength is directly related to ice thickness: as thickness increases, flexural strength increase and a higher transverse load is required to fail the ice in bending. Compressive strength is not geometry-related, and if the in-plane load becomes high enough before flexural failure can occur, the failure mode will again be dominated by crushing. Indentor velocity affects the downward 
acceleration of the ice sheet and the resulting hydrodynamic inertia, as described by Sorensen (1978). At very high velocities this inertia can impede the transverse deflection of the ice sheet required for flexucal failure, and crushing failure can result. These phenomenon were all observed in the present test series: the failure mode became dominated by crushing as indentor angle decreased, as ice thickness increased and indentor velocity increased. A "failure mode map" illustrating this transition (inspired by similar "maps" developed by Timco (1986) and others for vertical structures) was developed and is presented in Figure 5.4.

The largest peak horizontal force on the indentor was $32.7 \mathrm{kN}$, due to crushing failure. The normalized peak horizontal force $H$ increased as the indentor approachud vertical and crushing emerged as the dominant failure mode. For tests where flexural failure dominated (indentor angle $\alpha>10^{\circ}$ ), the function $H=1.3 \tan \left(90-\alpha+4^{\circ}\right)$ provided a good fit to experimental results. An exponentially increasing horizontal force with decreasing indentor angle has been observed and reported by several other researchers, as reported by Sodhi (1986).

A subsidiary cracking phenomenon was observed for many flexural failure events. A principal circumferential crack formed at a distance close to the characteristic length of the ice sheet, followed by one or two subsidiary circumferential cracks closer to the indentor face. High in-plane forces combined with vertical deflection of the ice sheet produced a shear and buckling failure responsible for this subsidiary cracking. The broken ice pieces generated by flexural failure events were subsequently smaller than those predicted by many previous authors, who do not document the formation of any subsidiary cracks. The distance of the initial flexural crack, however, is in agreement with the broken piece lengths reported by Frederking and Timco (1985) and Michel and Picard (1987). 


\section{References}

Bercha, F.G. and Danys, J.F., 1975. "Prediction of ice Srces on Offshore Conical Structures", Marine Science Communications, Vol.1, pp.365-380.

Blanchet, D., Churcher, A., Fitzpatrick, J. and Badra-Blanchet, P., 1989. "An Analysis of Observed Failure Mechanisms for Laboratory, First-Ycar and Multi-Year Icen, in 4th State-of-the-Art Report of the IAHR Working Group on Ice Forces, (G.W. Timco, editor), Special Report 89-5, pp.77-124.

Blenkarn, K.A., 1970. "Measurement and Analysis of Ice Forces on Cook Inlet. Structures", Proc. 2nd Offshore Technology Conference, Houston, Texas, OTC 1261, Vol.2, pp.365-378.

Cole, D.M., 1989. "Microfracture and the Compressive Failure of Polycrystalline Ice", Proc. IUTAM/IA HR Symposium on Ice-Structure Interaction, St. John's, Nfld., (in press).

Daoud, N. and Lee, F.C., 1986. "Ice-Induced Dynamic Loads on Offshore Structures", Proc. 5th International Offshore Mechanics and Arctic Engincering (OMAE) Symposium, ASME, Tokyo, Japan, Vol.4, pp.212-218.

Dieter, G.E., 1974. Mechanical Metallurgy, McGraw Hill, New York.

Eranti, E., Haynes, D., Määttänen, M. and Soong, T., 1981. "Dynamic IceStructure Interaction Analysis for Narrow Vertical Structures", Proc. 7th International Conference on Port and Ocean Engineering Under Arctic Conditions, Quebec City, Canada, Vol.1, pp.472-479.

Ettema, R. and Stern, F., 1989. "Dynamics of Continuous Icebreaking by an Icebreaker Hull", Proc. IUTAM/IAHR Symposium on Ice-Struciure Intcraction, St. John's, Nfld., (in press).

Frederking, R.G.W. and Timco, G.W., 1985. "Quantitative Analysis of Ice Sheet Failure Against an Inclined Plane", Proc. \&th International Offshore Mechanics and Arctic Engineering (OMAE) Symposium, ASME, Dallas, Texat, Vol.2, pp.160-169.

Frederking, R.G.W, and Timco, G.W., 1987. "Ice Loads on a Rigid Structure with a Compliant Foundation", Proc. Sth International Conference on Port and Ocean Engineering Under Arctic Conditions, Fairbanks, Alaska, Vol.3, pp.409-418.

Haynes, F.D., Sodhi, D.S., Kato, K, and Hirayama, K., 1983. "Ice Forces on Model Bridge Piers", US Army Cold Regions Research and Engineering Laboratory, Hanover, NH, CRREL Report 83-19. 
Hirayama, K., Schwarz, J. and Wu, H., 1974. "An Investigation of Ice Forces on Vertical Structures", University of Iowa, lowa City, lowa, lowa Institute of Hydraulic Research Report No.158.

Hirayarna, K. and Obara, I., 1986. "Ice Forces on Luclined Structures", Proc. 5th International Offshore Mechanics and Arctic Engineering (OMIAE) Symposium, ASME, Tokyo, Japan, Vol.4, pp.515.520.

Jebaraj, C., McKenna, R.F., Swamidas, A.S.J. and Jordaan, I.J., 1990. "Modelling of the Ice Failure Processes is Ship/Ice Interaction", Ocean Engineering Research Center, Faculty of Engineering, Memorial University of Newfoundland, Interim report submitted to Institute for Marine Dynamics, 67 .

Jebaraj, C., Swamidas, A.S.J. and Jones, S.D., 1988. "Dynamics of Ship/Ice Interaction", Proc. fro, the International Conference on Technolngy for Polar Areas - POLARTECH 88, Trondhcim, Norway, Vol.1, pp.89-100.

Jones, S.J., 1987. "Ice Tank Model Test Procedures at the Institute for Marine Dynamics", Institute for Marine Dynamics, St. John's, Nfld., NRC.IMD Internal Report LM-AVR-20, 25p.

Jordaan, I.J. and Timco, G.W., 1988. "Dynamics of the Ice Crushing Process", Journal of Glaciology, Vol.34, No.118, pp.318-325.

Jordaan, I.J., Kennedy, K.P., McKenna, R.F. and Maes, M.A., 1991. "Load and Vibration Induced by Compressive Failure of Ice", Proc. Sirth Inlernational Specialty Conference on Cold Regions Engineering (ASCE), Itanover, NII, pp.638-649.

Kärnä, T. and Turunen, R., 1990. "A Straightforward Technique for Analysing Structural Response to Dynamic Ice Action", Proc. 9th International Conference on Ofishore Mechanics and Arctic Engineering, Houston, Texas, Vol.4, pp.135-142.

Kenny, S., Meaney, R., Stone, B. and Jordaan, I.J., 1991. "Failure Zone Characterization: Medium-Scale Field Indentation Program, Hobson's Choice Ice Island 1990", Report submitted to the National Research Council Canada, Ottawa, Ontario.

Lipsett, A.W. and Gerard, R., 1980. "Field Measurements of Ice Forces on Bridge Piers, 1973-1979", Alberta Research Council, Edmonton, Alberta, Repor: No. SWE 80-3.

Mäăttänen, M., 1978. "On Conditions for the Rise of Self-Excited Ice-Induced Autonomous Oscillations in Slender Marine Structures", Finnish-Swedish Winter Navigation Board, Finland, Research Report 25, 98p. 
Määttänen, M., 1986. "Ice Sheet Failure Against an Inclined Wall", Proc. 7th IAHR Ice Symposium, Iowa City, lowa, Vol.1, pp.149-158.

Määttänen, M., 1988. "Ice-Induced Vibrations of Structures - Self-Excitation", Proc. 9th IAHR Ice Symposium, Sapporo, Japan, Vol.2, pp.658-665.

Matlock, H., Dawkins, W.P. and Panak, J.J., 1969. "A Model for the Prediction of Ice-Structure Interaction", Proc. Ist Offshore Technology Conference, Houston, Texas, OTC 1066, Vol.I, pp.687-694.

Miichcl, B., 1978. Ice Mechanics, Les Presses de l'Universite Iaval, Quebec.

Michel, B. and Blanchet, D., 1983. "Indentation of an S2 Floating Ice Sheet in the Brittle Range", Annals of Glaciology, Vol.4, pp.180-187.

Michel, B. and Picard, 1989. "Major Differences in the Failure Modes of an Ice Sheet on an Inclined Plane: Laboratory Tests", Proc. 10th International Conference on Port and Ocean Engineering Linder Arctic Conditions, Luleå, Sweden, Vol.1, pp.235-243.

Nakazawa, N.and Sodhi, D.S., 1990. "Ice Forces on Flat, Vertical Indentors Pushed Through Floating Ice Sheets" US Army Cold Regions Research and Engineering Laboratory, Hanover, NH, CRREL Special Report 90-14, 66p.

Neill, C. 1976. "Dynamic Ice Forces on Piles and Piers: An Assessment of Design Guidelines in Light of Recent Research", Canadian Journal of Civil Engineering, Vol.3, pp.305-341.

Nevel, D.E., 1972. "The Ultimate Failure of a Floating Ice Sheet", IAHR Ice Symposium, Leningrad, pp.17-22.

Peyton, H., 1968. “Sea Ice Forces - Ice Pressure Against Structures”, National Research Council of Canada, Technical Memorandum 92, pp.117-123.

Rao, S.S., 1986. Mechanical Vibrations, Addison-Wesley Publishing Cumpany, Inc., Reading, Massachusetts.

Sanderson, T.J.O., 1986. "A Pressure-Area Curve for Ice", Proc. 7th IAHR Ice Symposium, Iowa City, Iowa, Vol.2, pp.361-384.

Singh, S.K., Timco, G.W., Frederking, R.M.W. and Jordaan, 1.J., 1990. "Tests of Ice Crushing on a Flexible Structure", Proc. Ith International Conference on Offshore Mechanics and Arctic Engineering, Houston, Texas, Vol.4, pp.89-94.

Sodhi, D.S., 1987. "Dynamic Analysis of Failure Modes on Ice Sheets Encountering Sloping Structures", Proc. 6th International Conference on Ofjshore Mechanics and Arctic Engineering, Houston, Texas, Vol.4, pp.281-284. 
Sodhi, D.S., 1986. "Flexural and Buckling Failure of Floating Ice Sheets Against Structures", Proc. 7th IAHR Ice Sympesium, Iowa City, lowa, Vol.1, pp.339359.

Sodhi, D.S., 1988. "Ice-Induced Vibrations of Structures", Proc. 9th IA HR Ice Symposium, Sapporo, Japan, Vol.2, pp.625-657.

Solhi, D.S. and Morris, C.E., 1986. "Characteristic Frequency of Force Variations in Continuous Crushing of Sheet Ice Against Rigid Cylindricai Structures", Cold Regions Science and Technology, No.12, Vol.1, pp.1-12.

Sørensen, C., 1978. "Interaction Between Floating Ice Sheets and Sloping Structures", Institute of Hydrodynamics and Hydraulic Engineering, Technical University of Denmark, Series Paper No.19, 177p.

Timco, G.W., 1984. "Model Tests of Ice Forces on a Wide Inclined Plane", Proc. 5th IAHR Ice Syi: posium, Hamburg, Germany, Vol.2, pp.87-96.

Timco, G.W., 1986. "Indentation and Penetration of Edge-Loaded Freshwater lce Sheets in the Brittle Range", Proc. 5th International Symposium on Offshore Mechanics and Arctic Engineering, Tokyo, Japan, Vol.4, pp.4.4. 452.

Tomin, M.J., Cheung, M., Jordaan, I.J. and Cormeau, A., 1986. "Analysis of Failure Modes and Damage Processes of Freshwater Ice in Indentation Tests" Proc. 5th International Symposium on Offshore Mechanics and Arclic Engineering, Tokyo, Japan, Vol.4, pp.453-460.

Toyama, Y., Sensu, T. and Yashima, N., 1983. "Model Tests on Ice-Induced SelfExcited Vibration of Cylindrical Structures", Proc. 71h International Conference on Port and Ocean Engineering Under Arctic Conditions, Helsinki, Finland, Vol.2, pp.834-844.

Tsuchiya, M., Kanie, S., Ikejiri, K., Yoshida, A. and Sacki, H., 1985. "An Experimentel Study on Ice-Structure Interaction", Proc. I7th International Offshore Technology Conference, Houston, Texas, pp.321-327.

Valanto. P., 1989. "Experimental Study of the Icebrcaking Cycle in 2-D", Proc. 8th International Conference on Offshore Mechanics and Arctic Engineering, The Hague, Vol.4, pp.343-349.

Wessels, E. and Kato, K., 1988. "Ice Forces on Fixed and Floating Conical Structures", Proc. 9th International IAHR Symposium on Ice, Sapporo, Japan, Vol.2, pp.666-691.

Zabilansky, L.J., Nevel, D.E. and Haynes, F.D., 1975. "Ice Forces on Model Structures" Canadian Journal of Civil Engineering, Vol.2, pp.400-417. 
Appendix A

\section{VERTICAL INDENTATION}

\section{DATA}



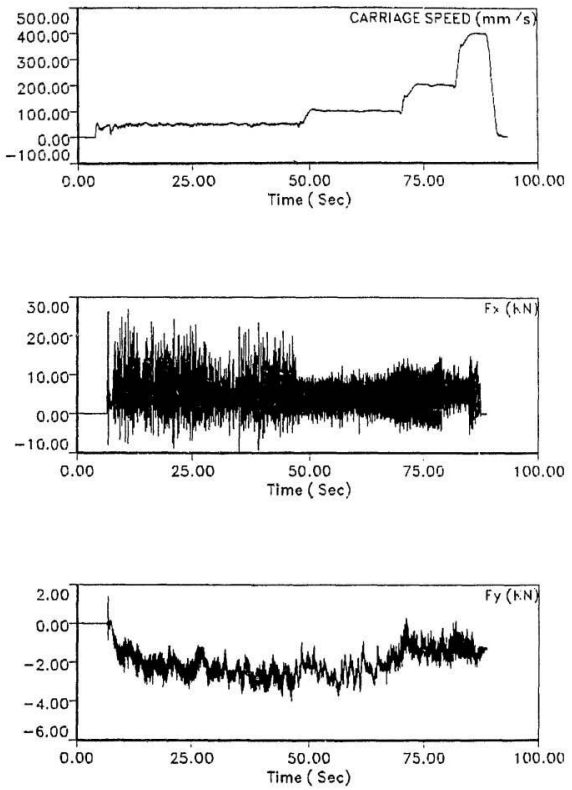

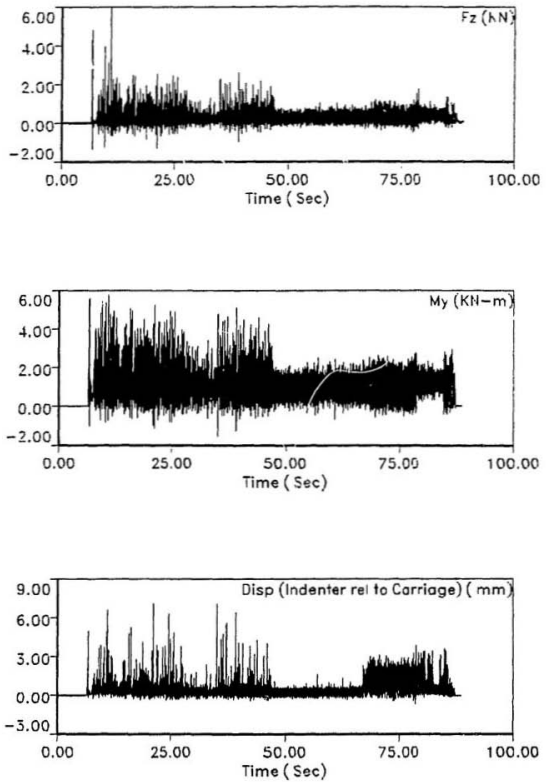

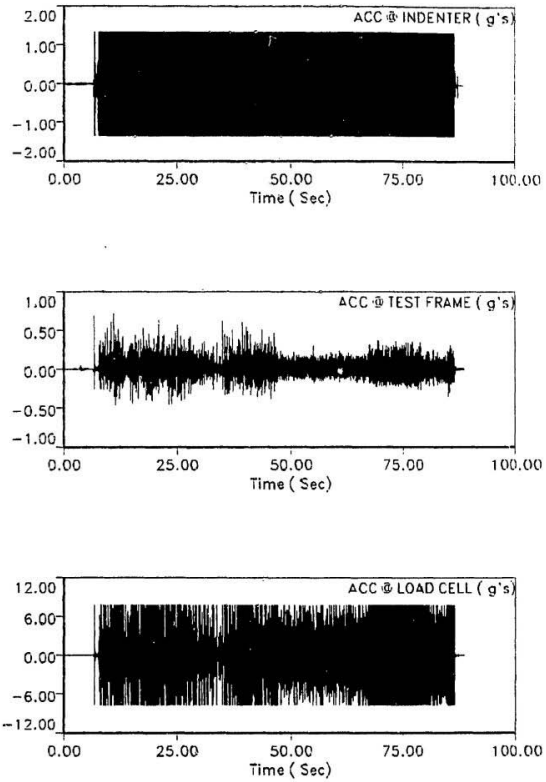

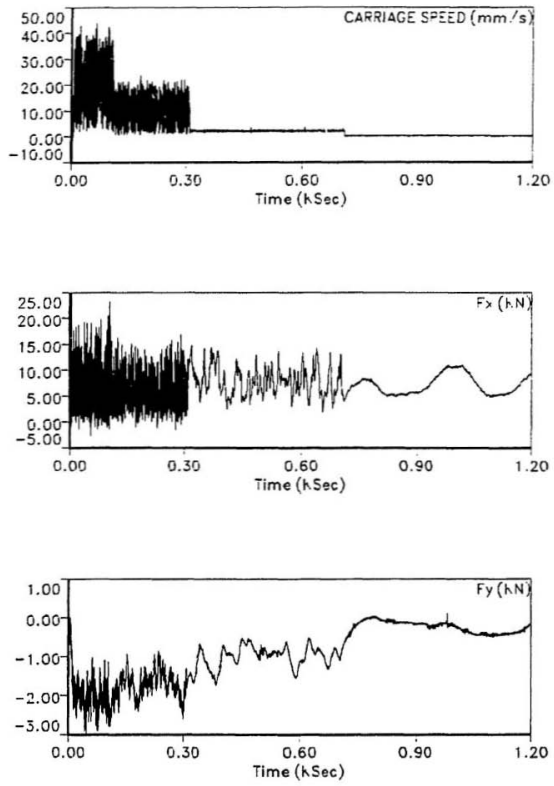

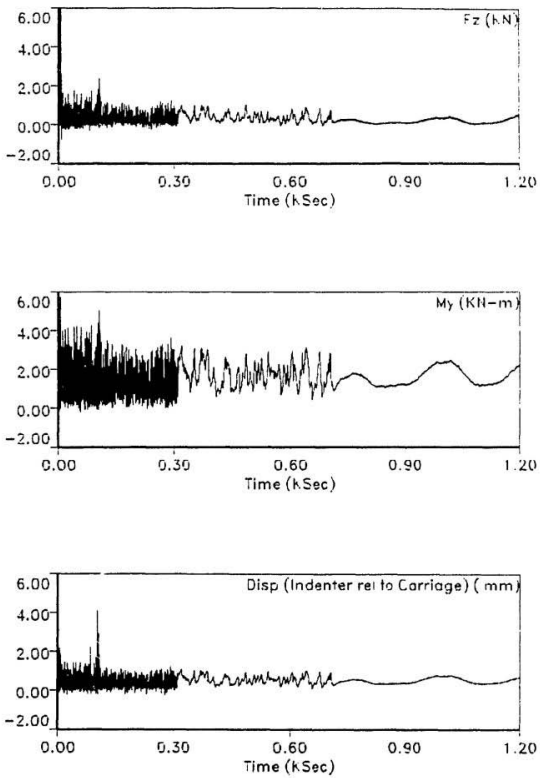

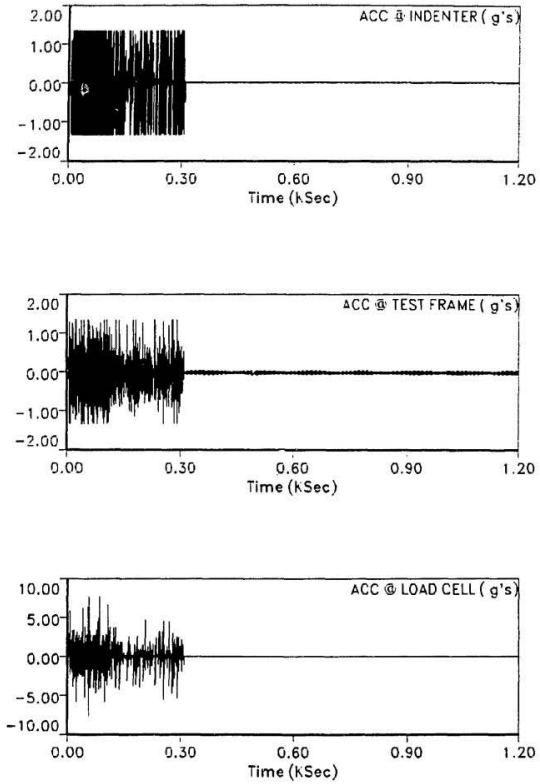
Appendix B

\section{INCLINED INDENTATION}

\section{DATA}



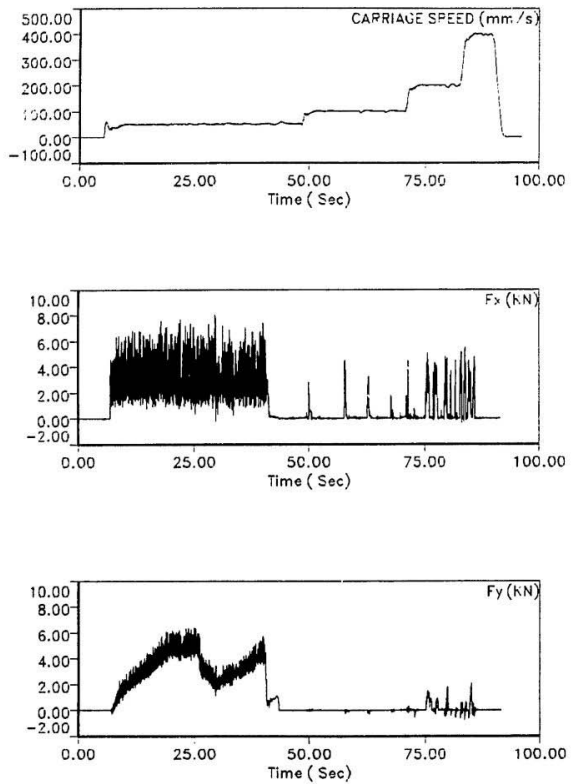

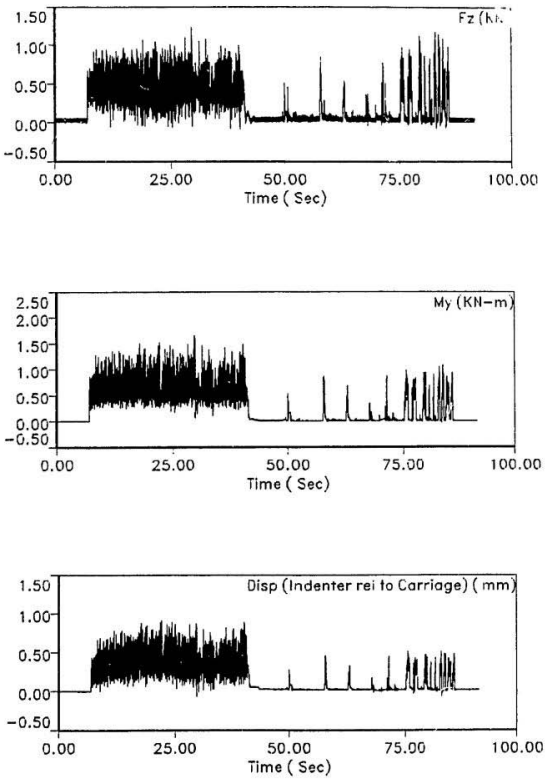

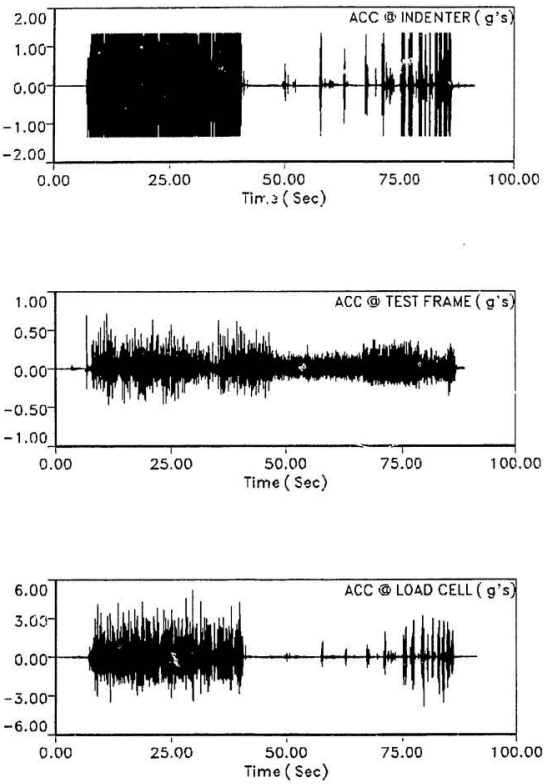

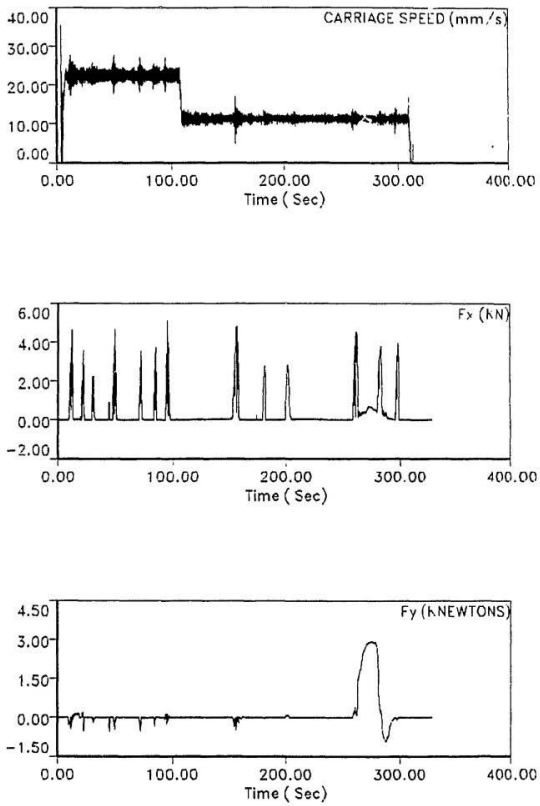

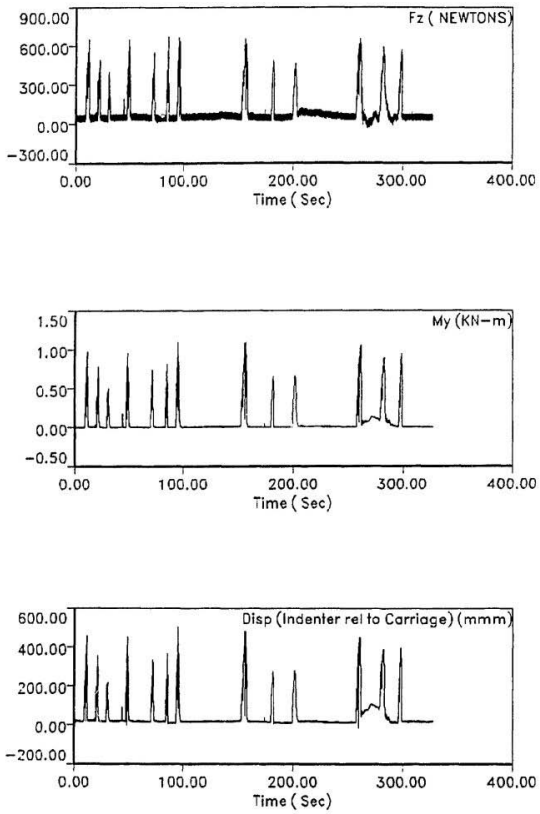

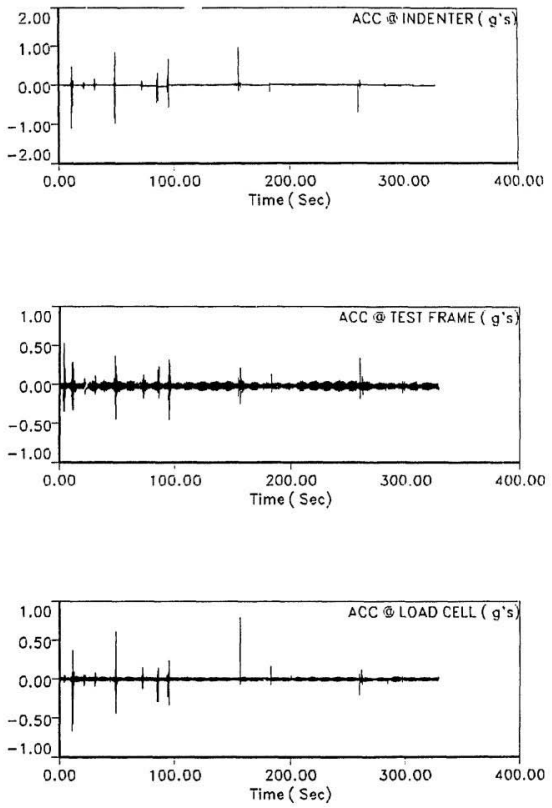



